\title{
Nanolayered composite with enhanced ultraviolet ray absorption properties from simultaneous intercalation of sunscreen molecules
}

This article was published in the following Dove Press journal: International Journal of Nanomedicine

\section{Sumaiyah Megat Nabil Mohsin,' Mohd Zobir Hussein, ${ }^{2}$ Siti Halimah Sarijo, ${ }^{3}$ Sharida Fakurazi, ${ }^{4,5}$ Palanisamy Arulselvan, ${ }^{6,7}$ Yun Hin Taufiq-Yap ${ }^{8}$ \\ 'Advanced Oleochemical Technology Division (AOTD), Malaysian Palm Oil Board (MPOB), Kajang, Selangor, Malaysia; ${ }^{2}$ Material Synthesis and Characterization Laboratory (MSCL), Institute of Advanced Technology (ITMA), Universiti Putra Malaysia, Serdang, Selangor, Malaysia; ${ }^{3}$ Faculty of Applied Science, Universiti Teknologi MARA, Shah Alam, Selangor, Malaysia; ${ }^{4}$ Department of Human Anatomy, Faculty of Medicine and Health Sciences, Universiti Putra Malaysia, Serdang, Selangor, Malaysia; ${ }^{5}$ Laboratory of Vaccines and Immunotherapeutics, Institute of Bioscience, Universiti Putra Malaysia, Serdang, Selangor, Malaysia; ${ }^{6}$ Muthayammal Centre for Advanced Research, Muthayammal College of Arts and Science, Rasipuram, Namakkal, Tamil Nadu, India; ${ }^{7}$ Scigen Research and Innovation, Periyar Technology Business Incubator, Thanjavur, Tamil Nadu, India; ${ }^{8}$ Catalysis Science and Technology Research Centre, Faculty of Science, Universiti Putra Malaysia, Serdang, Selangor, Malaysia}

Correspondence: Sumaiyah Megat Nabil Mohsin

Advanced Oleochemical Technology Division (AOTD), Malaysian Palm Oil Board (MPOB), 6, Persiaran Institusi, Bandar Baru Bangi, Kajang, Selangor, 43000, Malaysia

Tel +60 387693990

Fax +60 389256197

Email sumaiyah@mpob.gov.my
Introduction: The potential of layered double hydroxide (LDH) as a host of multiple ultraviolet-ray absorbers was investigated by simultaneous intercalation of benzophenone 4 (B4) and Eusolex ${ }^{\circledR} 232$ (EUS) in Zn/Al LDH.

Methods: The nanocomposites were prepared via coprecipitation method at various molar ratios of B4 and EUS.

Results: At equal molar ratios, the obtained nanocomposite showed an intercalation selectivity that is preferential to EUS. However, the selectivity ratio of intercalated anions was shown to be capable of being altered by adjusting the molar ratio of intended guests during synthesis. Dual-guest nanocomposite synthesized with B4:EUS molar ratio 3:1 (ZEB [3:1]) showed an intercalation selectivity ratio of $\mathrm{B} 4: \mathrm{EUS}=53: 47$. Properties of $\mathrm{ZEB}(3: 1)$ were monitored using powder X-ray diffractometer to show a basal spacing of $21.8 \AA$. Direct-injection mass spectra, Fourier transform infrared spectra, and ultraviolet-visible spectra confirmed the dual intercalation of both anions into the interlayer regions of dual-guest nanocomposite. The cytotoxicity study of dual-guest nanocomposite ZEB (3:1) on human dermal fibroblast cells showed no significant toxicity until $25 \mu \mathrm{g} / \mathrm{mL}$.

Conclusion: Overall, the findings demonstrate successful customization of ultraviolet-ray absorbers composition in LDH host.

Keywords: biocompatibility, cell viability, dermis, layered double hydroxide, nanocomposite

\section{Introduction}

Layered double hydroxides (LDHs) can be represented by the general formula $\left[\mathrm{M}^{\mathrm{II}}{ }_{1-x} \mathrm{M}_{x}^{\mathrm{III}}(\mathrm{OH})_{2}\right]^{z+} \mathrm{A}^{n-}{ }_{z / n} \cdot y \mathrm{H}_{2} \mathrm{O}$ where $\mathrm{A}^{n-}$ is the interlayer anion, and $\mathrm{M}^{\mathrm{II}}$ and $\mathrm{M}^{\mathrm{III}}$ are di- and trivalent metallic cation, respectively. ${ }^{1} \mathrm{LDH}$ consists of a structure with positively charged layers that are electrically balanced by interlayer anions. The interlayer anion can be exchanged with a variety of inorganic and organic anions. Thus, the interlayer region of the layered material can be considered as a nanovessel in which anionic molecule can be stored.

Application of the layered material as a nanometer-sized host has garnered considerable attention due to its good biocompatibility, low cytotoxicity, ease of laboratory preparation, and ease of tailoring for required physical and chemical properties. ${ }^{1-5}$ Simultaneous intercalation of two or more anions into the interlayer region of LDH was previously attempted with amino acids, ${ }^{6}$ ligand and ligation activator, ${ }^{7}$ diagnosis and therapy agents, ${ }^{8-10}$ herbicides, ${ }^{11-13}$ polymers,${ }^{14}$ nucleoside monophosphates, ${ }^{15}$ and isomeric benzoates. ${ }^{16}$ There is a notable paucity of scientific literature investigating interlayer region intercalation of two or more ultraviolet (UV) ray absorbents. submit your manuscript

Dovepress

$f y$ in 0

in 2 cC. hereby accept the Terms. Non-commercial uses of the work are permitted without any further permission from Dove Medical Press Limited, provided the work is properly attributed. For permission for commercial use of this work, please see paragraphs 4.2 and 5 of our Terms (https://www.dovepress.com/terms.php). 
Eusolex $^{\circledR} 232$ (2-phenylbenzimidazole-5-sulfonic acid or EUS) is often found in sunscreen formulations due to its intense absorption at UVB wavelengths. In the past, major concerns were expressed on the usage EUS as studies on photophysical and photochemical characteristic of EUS have demonstrated the capacity of EUS to generate reactive oxygen species, including singlet oxygen, upon photoexcitation. In the cellular context, the findings suggest that the photodegraded product of EUS could possibly damage DNA, as well as proteins and lipids, through a photosensitizing mechanism. ${ }^{17,18}$ Another UV ray absorbent, benzophenone 4 (2-hydroxy-4-methoxybenzophenone-5sulfonic acid or B4) is often used as active ingredient in sunscreens as it provides shielding in a broad UV spectrum and also prevents other compounds from degrading. However, recent studies have found that benzophenones are relatively easy to be absorbed into the skin and have been shown to promote generation of reactive oxygen species and display harmful properties. ${ }^{19-21}$

In our previous work, we have prepared $\mathrm{Zn} / \mathrm{Al}-\mathrm{LDH}$ intercalated with B4 and EUS separately. The resulting nanocomposites have shown an increase in UV ray absorption capability compared to their bulk counterparts. Additionally, simulation under skin $\mathrm{pH}$ medium demonstrated low release of the intercalated UV ray absorbents over an extended period of time. ${ }^{22}$ In the present work, we propose simultaneous intercalation of B4 and EUS into Zn/Al-LDH via coprecipitation method. The expected advantages of encapsulating organic UV ray absorbents within the interlayer region of LDHs are 1) increased photostability, 2) decreased release from formulation to skin, and 3) absence of direct contact with skin while maintaining UV ray absorption properties of anionic guest. Cointercalation by two anionic guests is expected to exhibit selective intercalation that is influenced by guest-host interaction. Our work aims to examine factors that influence the selectivity, as well as determine whether the selectivity could be altered. The present study will help elucidate the effect of intercalation of more than one organic sunscreen molecules in LDH on the resulting thermal property, surface property, controlled release property, and $\mathrm{UV}$ ray absorptivity of the resulting nanocomposites.

\section{Materials and methods Materials}

B4 (99.0\%) was purchased from Norquay Technologies (Chester, PA, USA). Zinc nitrate hexahydrate (99.0\%) and aluminum nitrate nanohydrate $(99.0 \%)$ were obtained from PC Laboratory Chemicals (Mumbai, India) and used without further purification. EUS (99.0\%) and sodium hydroxide $(99.0 \%)$ from Merck (Darmstadt, Germany), dimethyl sulfoxide (DMSO) and phosphate buffer solution from
Sigma-Aldrich (St Louis, MO, USA) and sodium chloride (99.0\%) from HmbG Chemicals (Hamburg, Germany) were also used without further purifications.

\section{Synthesis of $\mathrm{Zn} / \mathrm{Al}-\mathrm{NO}_{3} \mathrm{LDH}$}

$\mathrm{Zn} / \mathrm{Al}^{-\mathrm{NO}_{3}} \mathrm{LDH}$ with $\mathrm{Zn}$ to $\mathrm{Al}$ molar ratio, $R=2$ was prepared as follows. A $250 \mathrm{~mL}$ mixture containing $0.1 \mathrm{~mol} / \mathrm{L}$ $\mathrm{Zn}\left(\mathrm{NO}_{3}\right)_{2} \cdot 6 \mathrm{H}_{2} \mathrm{O}$ and $0.05 \mathrm{~mol} / \mathrm{L} \mathrm{Al}\left(\mathrm{NO}_{3}\right)_{3} \cdot 9 \mathrm{H}_{2} \mathrm{O}$ was precipitated with $0.5 \mathrm{~mol} / \mathrm{L} \mathrm{NaOH}$ solution under nitrogen atmosphere until the final $\mathrm{pH}$ of 7 was reached. The resulting white slurry was aged in an oil bath shaker at $70^{\circ} \mathrm{C}$ for $18 \mathrm{~h}$. The resulting precipitate was retrieved via centrifugation, rinsed with deionized water several times, and dried in an oven at $70^{\circ} \mathrm{C}$ for 3 days. The dried LDH was powdered using a mortar and pestle.

\section{Synthesis of dual-guest Zn/Al-LDH nanocomposite}

Dual-guest Zn/Al-LDH nanocomposite was prepared by mixing $100 \mathrm{~mL}$ of EUS and B4 mixture solutions into $100 \mathrm{~mL}$ of $0.1 \mathrm{~mol} / \mathrm{L} \mathrm{Zn}\left(\mathrm{NO}_{3}\right)_{2} \cdot 6 \mathrm{H}_{2} \mathrm{O}$ and $0.05 \mathrm{~mol} / \mathrm{L} \mathrm{Al}\left(\mathrm{NO}_{3}\right)_{3} \cdot 9 \mathrm{H}_{2} \mathrm{O}$ under nitrogen atmosphere and vigorous stirring. The $\mathrm{B} 4$ and EUS mixture was prepared by keeping the concentration of B4 constant at $0.1 \mathrm{~mol} / \mathrm{L}$ while varying the concentration of EUS at $0.1,0.05,0.033$, and $0.025 \mathrm{~mol} / \mathrm{L}$ to obtain B4 to EUS molar ratios of $1: 1,2: 1,3: 1$, and $4: 1$, respectively. The final $\mathrm{pH}$ of the solution was controlled to 8 by dropwise addition of $0.5 \mathrm{~mol} / \mathrm{L} \mathrm{NaOH}$ solution. The resulting light yellow slurry was placed in an oil bath shaker at $70^{\circ} \mathrm{C}$ for $18 \mathrm{~h}$, before being centrifuged and rinsed with deionized water. The final light yellow solid (dual-guest nanocomposite samples) was dried in an oven at $70^{\circ} \mathrm{C}$ overnight and powdered using a mortar and pestle.

\section{Characterization}

Powder X-ray diffraction (PXRD) patterns were recorded using an XRD-6000 (Shimadzu, Kyoto, Japan) using $\mathrm{CuK}_{\alpha}$ radiation $(\lambda=1.5418 \AA$ ). Fourier transform infrared (FTIR) spectra were recorded over the range of $400-4,000 \mathrm{~cm}^{-1}$ on a 1752X spectrophotometer (Perkin-Elmer, Waltham, MA, USA). Samples in solid state were measured in $\mathrm{KBr}$ matrix pellet obtained with a hydraulic press under $10 \mathrm{kPa}$ pressure for 5 minutes. The carbon, hydrogen, and nitrogen contents in the nanocomposites were analyzed on a CHNS-932 (LECO Instruments, St Joseph, MI, USA). The metal contents of the nanocomposites were determined by inductively coupled plasma atomic emission spectrometry (ICP-AES) using a Perkin-Elmer spectrophotometer model Optima 2000DV (Perkin-Elmer) under standard conditions. Thermogravimetric and differential thermogravimetric analyses (TGA/DTG) were performed on a 
Mettler-Toledo instrument model TGA851e (Mettler-Toledo, Greifensee, Switzerland) at a heating rate of $10^{\circ} \mathrm{C} / \mathrm{min}$ in the range of $25^{\circ} \mathrm{C}-1,000^{\circ} \mathrm{C}$. Surface characterization of the materials was carried out using a nitrogen gas adsorption-desorption technique at $77 \mathrm{~K}$ using Micromeritics, ASAP2000 (Micromeritics Instrument Corporation, Norcross, GA, USA). The surface morphology of the samples was observed by a field emission scanning electron microscopy (FESEM) using a ZEISS supra 40VP (Carl Zeiss, Oberkochen, German), and optical measurements were performed on a Shimadzu UV-visible (VIS)-near infrared (NIR) diffuse reflectance spectrometer (UV-3600 model). Direct-injection mass spectroscopy (DIMS) was performed using a Shimadzu DIMS QP5050A.

\section{Simultaneous release of B4 and EUS from $\mathrm{LDH}$ nanocomposites}

Simultaneous release of B4 and EUS anions from LDH host against time was measured in situ at $\lambda_{\text {max }}=285$ and 311 $\mathrm{nm}$ for B4 and EUS, respectively, using a Perkin-Elmer UV-VIS spectrometer Lambda 35 (Perkin-Elmer) by adding $0.2 \mathrm{mg}$ of sample into $3.5 \mathrm{~mL}$ of $0.5 \mathrm{~mol} / \mathrm{L} \mathrm{NaCl}$ and $\mathrm{pH} 5.5$ phosphate buffer solution at room temperature. Data were collected and fit into zero-, first-, pseudo-second order, and parabolic diffusion kinetic models.

\section{Culture of human dermal fibroblasts}

Human dermal fibroblasts (HDFs) were obtained from American Type Culture Collection (ATCC), (Manassas, VA, USA) and cultured at $37^{\circ} \mathrm{C}$ in a humidified atmosphere of 5\% $\mathrm{CO}_{2}$ with high glucose Dulbecco's Modified Eagle's Medium (ScienCellResearch Laboratories, Carlsbad, CA, USA) containing $2 \%$ fetal bovine serum, $0.5 \%$ penicillinstreptomycin, $1 \%$ glutamine, and $1 \%$ nonessential amino acids. For the experiment, we used a seeding density of $1 \times 10^{5}$ cells/well plated onto 96-well plates.

\section{Cell viability assay}

The cell cytotoxicity was determined by MTT colorimetric method. ${ }^{23}$ In brief, cells were cultured in 96-well plates at a density of $1 \times 10^{5}$ cells/well for cytotoxicity assessment study. After being incubated for $24 \mathrm{~h}$, the cells were treated to various concentrations of test compounds including synthesized nanocomposites and incubated for $24 \mathrm{~h}$. After the specific incubation period, freshly prepared tetrazolium dye (MTT; Sigma-Aldrich Co., St Louis, MO, USA) was added and then converted to purple formazan. The formazan product was dissolved with $100 \mu \mathrm{L}$ of DMSO which was added to each well. Finally, the formazan concentration from the 96-well plates was measured at $570 \mathrm{~nm}$ using an enzyme-linked immunosorbent assay microplate reader. Cell viability was calculated as a ratio of various test compounds exposed cells to control cells.

\section{Results and discussion X-ray diffraction and spatial orientation of the guest between LDH interlayers}

The PXRD pattern and average basal spacing of pristine $\mathrm{Zn}$ / $\mathrm{Al}-\mathrm{NO}_{3}-\mathrm{LDH}$ as well as dual-guest nanocomposite samples are shown in Figure 1. Average basal spacing of $\mathrm{Zn} / \mathrm{Al}-\mathrm{NO}_{3}$

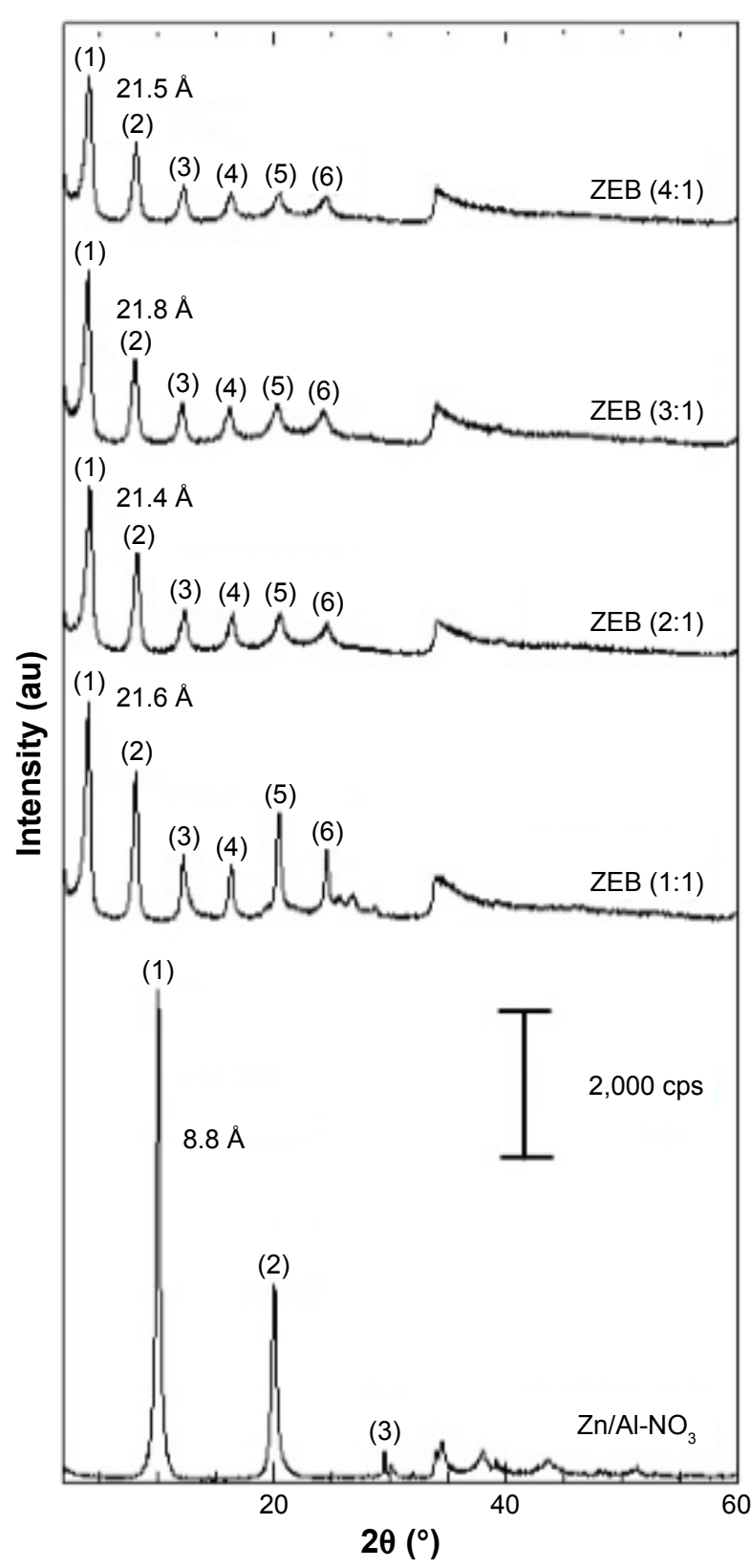

Figure I PXRD patterns of $\mathrm{Zn} / \mathrm{Al}-\mathrm{NO}_{3}$ and dual-guest nanocomposites prepared at various $B 4: E U S$ molar ratios.

Abbreviations: B4, benzophenone 4; EUS, Eusolex ${ }^{\circledR} 232$; PXRD, powder X-ray diffraction; ZEB, dual-guest nanocomposite synthesized with B4 and EUS. 
Table I Empirical formula and d-spacing of $\mathrm{Zn} / \mathrm{Al}-\mathrm{NO}_{3}$, and ZEB (3:I) nanocomposite

\begin{tabular}{lll}
\hline Samples & Empirical formula $^{\mathrm{a}}$ & $\begin{array}{l}\text { d-spacing } \\
(\mathbf{A})\end{array}$ \\
\hline $\mathrm{Zn} / \mathrm{Al}-\mathrm{NO}_{3}$ & {$\left[\mathrm{Zn}_{0.67} \mathrm{Al}_{0.33}(\mathrm{OH})_{2}\right]\left[\mathrm{NO}_{3}^{-}\right]_{0.33} \cdot 0.56 \mathrm{H}_{2} \mathrm{O}$} & $8.8^{\mathrm{b}}$ \\
$\mathrm{ZEB} \mathrm{(3:I)}$ & {$\left[\mathrm{Zn}_{0.69} \mathrm{Al}_{0.31}(\mathrm{OH})_{2}\right]\left[\left(\mathrm{C}_{14} \mathrm{H}_{11} \mathrm{O}_{6} \mathrm{~S}^{-}\right]_{0.16}\right.$} & $21.8^{\mathrm{c}}$ \\
& {$\left[\left(\mathrm{C}_{13} \mathrm{H}_{9} \mathrm{~N}_{2} \mathrm{O}_{3} \mathrm{~S}^{-}\right]_{0.16} \cdot 1.58 \mathrm{H}_{2} \mathrm{O}\right.$} & \\
\hline
\end{tabular}

Notes: ${ }^{a}$ Estimated from ICP-AES and TGA/DTG. ${ }^{b}$ Average basal spacing based on 2 harmonics. 'Average basal spacing based on 6 harmonics.

Abbreviations: ICP-AES, inductively coupled plasma atomic emission spectrometry; TGA/DTG, thermogravimetric and differential thermogravimetric analyses; ZEB (3:I), dual-guest nanocomposite synthesized with B4:EUS molar ratio 3:1.

and ZEB (3:1) nanocomposite based on 2 and 6 harmonics are summarized in Table 1

Factors such as anionic size, charge, orientation, and interaction with the positively charged inorganic interlayer affect the degree of intercalation and the separation between layers. $\mathrm{Zn} / \mathrm{Al}-\mathrm{NO}_{3}-\mathrm{LDH}$ showed basal spacing of $8.8 \AA$, a typical basal spacing shown by $\mathrm{Zn} / \mathrm{Al}-\mathrm{NO}_{3}-\mathrm{LDH}$ with nitrates as the counter anion. ${ }^{24}$ Increment in basal spacing in UV absorber/LDH nanocomposites is due to displacement of nitrates with larger organic UV absorbing molecules. In the case of dual-guest nanocomposite samples, little difference in average basal spacing could be detected by varying the molar ratios of B4 to EUS.

Estimated dimensions of B4 and EUS anions were obtained using ChemBioOffice software (Perkin-Elmer), as shown in Figure 2A and B. The anion geometry was optimized by applying molecular mechanical MM2 energy minimization calculation available in the software. Expected gallery height that can be occupied can be deducted by subtracting the layer thickness of $4.8 \AA$ from basal spacing obtained from PXRD analysis. A new monophasic dualguest nanocomposite was obtained with slightly larger basal spacing from values reported for single-guest intercalation of B4 (21.3 $\AA$ ) and EUS $(21.0 \AA) .{ }^{22}$ We could attribute this to the interaction of larger molecular size of EUS with B4. We foresee bilayer arrangement by alternating chargebalancing $\mathrm{SO}_{3}^{-}$groups above and below the layer with maximized $\pi-\pi$ interaction between the benzene rings. ${ }^{25}$ To form a bilayer arrangement, the most plausible orientation (Figure $2 \mathrm{C}$ ) with maximized $\pi-\pi$ interaction between molecules of different sizes would naturally have less compatibility than that of the same molecules. Thus, the slight increment in basal spacing compared to that of single-guest nanocomposites is expected.

\section{Elemental analyses}

The empirical formula of $\mathrm{Zn} / \mathrm{Al}-\mathrm{LDH}$ nanocomposites listed in Table 1, was determined from ICP-AES and TGA/DTG analyses. Chemical compositions of B4, EUS,

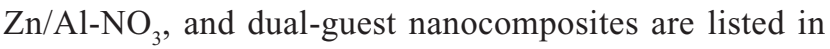
Table 2 .
A

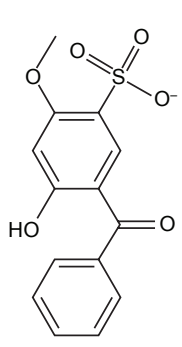

B

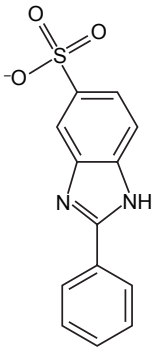

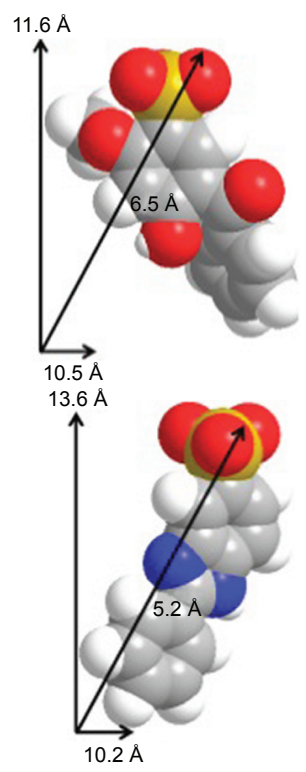

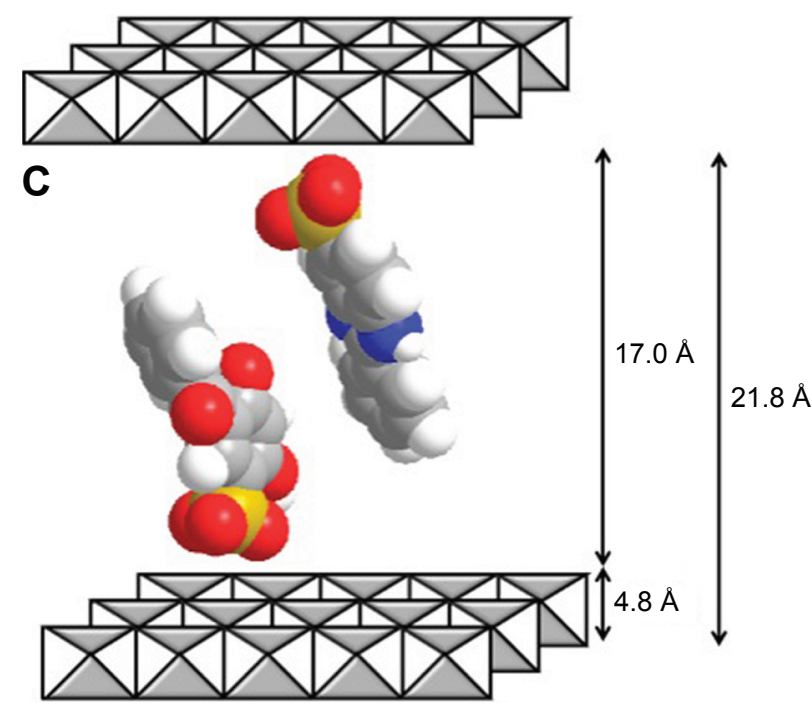

Hydrogen

Sulphur
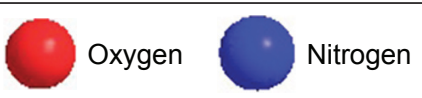

Figure 2 Molecular structure of and three-dimensional molecular size of B4 (A) and EUS (B) and proposed orientation of B4 and EUS in Zn/AI-LDH interlayer for the formation of dual-guest nanocomposite ZEB (3:1) (C).

Abbreviations: B4, benzophenone 4; EUS, Eusolex ${ }^{\circledR}$ 232; LDH, layered double hydroxide; ZEB (3:I), dual-guest nanocomposite synthesized with B4:EUS molar ratio 3:I. 
Table 2 Chemical compositions of B4, EUS, Zn/AI-NO, ZB4, ZEUS, and dual-guest nanocomposites

\begin{tabular}{lllllllll}
\hline Sample & $\mathbf{C}(\%)$ & $\mathbf{H}(\%)$ & $\mathbf{N}(\%)$ & $\mathbf{S ~ ( \% )}$ & $\mathbf{Z n}(\% \mathbf{w} / \mathbf{w})^{\mathbf{a}}$ & $\mathbf{A l}(\% \mathbf{w} / \mathbf{w})^{\mathbf{a}}$ & $\mathbf{Z n}^{2+} /\left.\mathbf{A}\right|^{3+\mathbf{a}}$ & $\mathbf{x}$ \\
\hline B4 & 47.5 & 5.2 & 0 & 10.0 & 0 & 0 & 0 & 0 \\
EUS & 54.8 & 3.1 & 17.0 & 9.7 & 0 & 0 & 0 \\
Zn/AIINO & 0.3 & 2.3 & 13.9 & 0.4 & 35.2 & 7.0 & 0 \\
ZEB (I:I) & 25.4 & 2.9 & 5.3 & 4.5 & 22.4 & 4.3 & 2.1 & 2.1 \\
ZEB (2:I) & 20.6 & 3.7 & 1.1 & 4.6 & 24.1 & 4.5 & 0.33 \\
ZEB (3:I) & 20.3 & 3.4 & 0.4 & 8.3 & 24.8 & 4.6 & 0.32 \\
ZEB (4:I) & 18.2 & 3.9 & 0.2 & 6.2 & 23.8 & 4.5 & 2.2 & 0.31 \\
\hline
\end{tabular}

Note: ${ }^{a}$ Estimated from ICP-AES analysis.

Abbreviations: ICP-AES, inductively coupled plasma atomic emission spectrometry; B4, benzophenone 4; EUS, Eusolex ${ }^{\circledR}$ 232; ZEB, dual-guest nanocomposite synthesized with B4 and EUS.

The $\mathrm{Zn} / \mathrm{Al}$ molar ratios for all $\mathrm{Zn} / \mathrm{Al}-\mathrm{LDH}$ samples obtained experimentally are slightly higher than the calculated value, $R=2$. The slight discrepancy between calculated and observed ratio is due to the requirement to adjust the $\mathrm{Zn}$ to $\mathrm{Al}$ ratio to neutralize the charge of the anions intercalated in between the LDH interlayers.

The amount of intercalated anions was determined using UV-VIS spectrometer by treating samples with acid to disintegrate inorganic layers completely, releasing the intercalated anions. Absorbance was monitored at $\lambda_{\max }=285$ and $311 \mathrm{~nm}$ for B4 and EUS, respectively. Percentage loading of the dual-guest nanocomposites was determined by solving simultaneous equation below:

$$
\begin{aligned}
& \text { at } \lambda_{1}: \mathrm{A}_{1}=\varepsilon_{\mathrm{B} 4} \times \mathrm{b} \times \mathrm{C}_{\mathrm{B} 4}+\varepsilon_{\mathrm{EUS}} \times \mathrm{b} \times \mathrm{C}_{\mathrm{EUS}} \\
& \text { at } \lambda_{2}: \mathrm{A}_{2}=\varepsilon_{\mathrm{B} 4}{ }^{\prime} \times \mathrm{b} \times \mathrm{C}_{\mathrm{B} 4}+\varepsilon_{\mathrm{EUS}}{ }^{\prime} \times \mathrm{b} \times \mathrm{C}_{\mathrm{EUS}}
\end{aligned}
$$

where $\lambda_{1}$ and $\lambda_{2}$ are random wavelength points. $A_{1}$ and $A_{2}$ indicate the absorbance for mixture solution containing both B4 and EUS, $\varepsilon$ is the absorptivity of each anion, $\mathrm{C}(\mathrm{mg} / \mathrm{L})$ represents the concentration of $100 \%$ release of anions, and $b$ is the path length $(1 \mathrm{~cm})$.

A summary of percentage loading of intercalated anion is listed in Table 3. Elemental analysis of dual-guest nanocomposites confirmed the cointercalation of both B4 and EUS into LDH. The results also reveal that the relative contents of the cointercalated guests in LDH could be controlled by

Table 3 Competitive intercalation between B4 and EUS at different B4:EUS ratios

\begin{tabular}{llll}
\hline Sample & $\begin{array}{l}\text { Percentage B4 } \\
\text { intercalated } \\
(\% w / w)\end{array}$ & $\begin{array}{l}\text { Percentage EUS } \\
\text { intercalated } \\
(\% w / w)\end{array}$ & $\begin{array}{l}\text { Selectivity } \\
\text { ratios B4:EUS }\end{array}$ \\
\hline ZEB (I:I) & 0.0 & 48.5 & $0: 100$ \\
ZEB (2:I) & 8.6 & 26.0 & $25: 75$ \\
ZEB (3:I) & 20.5 & 17.9 & $53: 47$ \\
ZEB (4:I) & 26.8 & 14.5 & $65: 35$ \\
\hline
\end{tabular}

Abbreviations: B4, benzophenone 4; EUS, Eusolex ${ }^{\circledR} 232$; ZEB, dual-guest nanocomposite synthesized with B4 and EUS. changing the ratio of guests in the reaction media. Although B4 loading was not detected in ZEB (1:1) sample, its PXRD result showed little difference in basal spacing in comparison to the rest. Therefore, it may be possible that some intercalation of B4 had occurred in negligible concentrations.

Simultaneous intercalation of B4 and EUS using the same B4:EUS ratios shows that LDH favors the intercalation of EUS. However, as molar ratio of B4 is increased and EUS is decreased, we could overcome the strong preference to EUS. Preferences to anion by an LDH are affected by the electrostatic attraction between positively charged metal hydroxide layer and the guest anions, hydrogen bonds between sulfoxyl oxygen atoms in the guest anions and hydroxyl hydrogen atoms in the hydroxide layers, and distribution of charges (dipole moment) in the guest anions. ${ }^{26}$ Unlike EUS, B4 has two substituent groups on its aromatic ring that could influence the distribution of charges. Electron-donating $-\mathrm{OH}$ on the para position of sulfoxylate group may be reinforcing B4's electrostatic attraction to the interlayer, but we believe that in the present case, the ortho position of electron-donating $-\mathrm{OCH}_{3}$ group has a more significant effect because they are able to interact with hydroxyl hydrogen atoms in the hydroxide layers. Hence, low selectivity of B4 could be attributed to the antagonistic effect of $-\mathrm{OCH}_{3}$ group on the ortho position of the sulfoxylate group. As summarized in Table 3, an almost equal amount of intercalated percentage of B4 and EUS was synthesized with B4:EUS molar ratio of 3:1. Therefore, further physicochemical characterizations, UV absorptivity, and cytotoxicity studies were focused on ZEB (3:1) nanocomposite.

\section{DIMS}

Mass spectral results of EUS, B4, and the dual-guest nanocomposite ZEB (3:1) are presented in Figure 3. DIMS serves as a fingerprinting tool to determine the intercalated components.

Mass spectra of pure EUS showed abundant peak at $\mathrm{m} / \mathrm{z} 274$ corresponding to its molecular ion peak. Molecular ion peak for B4 meanwhile was slightly less prominent and was preceded by M-1 peak at $\mathrm{m} / z 307$ resulting from the 

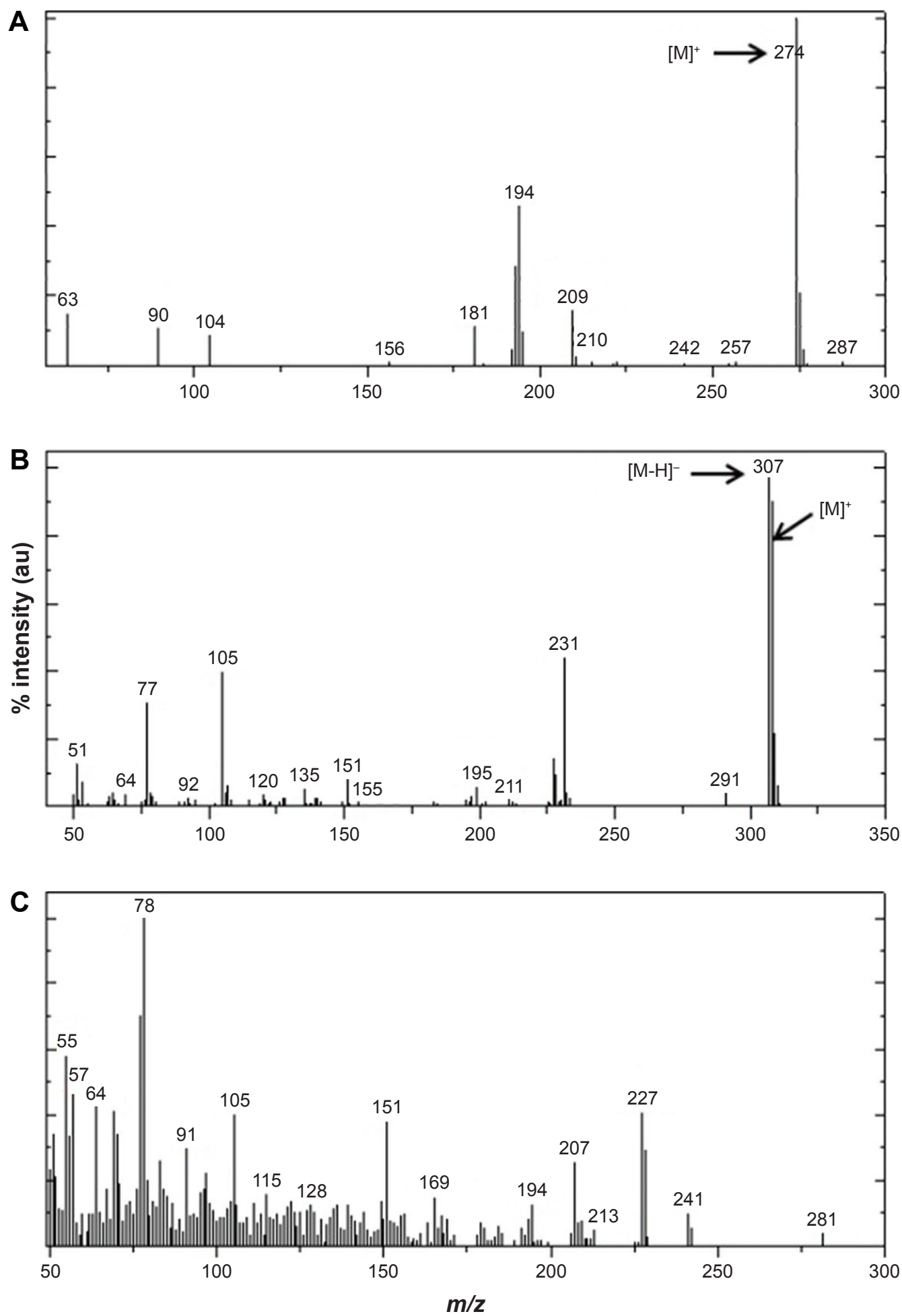

Figure 3 DIMS patterns of EUS (A), B4 (B), and dual-guest nanocomposite ZEB (3:I) (C).

Abbreviations: B4, benzophenone 4; DIMS, direct-injection mass spectroscopy; EUS, Eusolex ${ }^{\circledR} 232$; ZEB (3:I), dual-guest nanocomposite synthesized with B4:EUS molar ratio $3: 1$.

loss of hydrogen radical. We focused on ZEB (3:1) sample as it consisted of almost equal percentage of intercalated B4 and EUS. DIMS pattern of ZEB (3:1) gave rise to a peak at $m / z 194$, corresponding to $\left[\mathrm{C}_{13} \mathrm{H}_{10} \mathrm{~N}_{2}\right]^{+}$, a product of desulfonated fragment ion of EUS. The comparatively higher intensity of fragmentation ion $\left[\mathrm{C}_{7} \mathrm{H}_{3} \mathrm{O}\right]^{+}(\mathrm{m} / z$ 105) and $\left[\mathrm{C}_{8} \mathrm{H}_{7} \mathrm{O}\right]^{+}(\mathrm{m} / \mathrm{z} 151)$ comes from further fragmentation of desulfonated product of $\mathrm{B} 4\left[\mathrm{C}_{14} \mathrm{H}_{14} \mathrm{O}_{3}\right]^{+}(\mathrm{m} / z 231)$. High intensity 
at $m / z 78$ corresponds to deprotonated benzene which could be attributed to fragmentation of either intercalated anions. ${ }^{27,28}$ Peaks coinciding with molar mass of B4 and EUS could not be detected in our dual-guest nanocomposite. This phenomenon could be due to intermolecular bonding between dual-guest anions in the layered matrix that resulted in more complex mass fragmentation than a single-guest anion intercalation.

The observed fragmentation peaks confirm the cointercalation of both anions B4 and EUS in the LDH host. It is worth noting that ZEB (3:1) showed more prominent peaks assigned to B4 than EUS. The abundance of fragment ions representing B4 suggests higher intercalated ratio for B4 in the samples ZEB (3:1), which is in agreement with the results presented in Table 3.

\section{FTIR spectroscopy}

The FTIR spectra of B4, EUS, Zn/Al-NO , and dual-guest ZEB nanocomposites are displayed in Figure 4.

The FTIR spectra for both $\mathrm{Zn} / \mathrm{Al}-\mathrm{NO}_{3}$ and dual-guest nanocomposites show a broad absorption band commonly observed in the LDH materials centered at around $3,500 \mathrm{~cm}^{-1}$ due to the presence of O-H stretching mode of the hydroxyl group physisorbed onto LDH layers, as well as interlayer water molecules. ${ }^{29} \mathrm{~A}$ weak band corresponding to the stretching vibration of $\mathrm{H}-\mathrm{OH}$ appears at $1,628 \mathrm{~cm}^{-1} .{ }^{30}$ Bands in the low-frequency region correspond to translational vibration modes of $\mathrm{Zn}-\mathrm{OH}$ at $611-615 \mathrm{~cm}^{-1}, \mathrm{Al}-\mathrm{OH}$ at around $554 \mathrm{~cm}^{-1}$, and deformation of HO-Zn-Al-OH at $425 \mathrm{~cm}^{-1}$. A sharp peak at $1,384 \mathrm{~cm}^{-1}$ is attributed to $\mathrm{NO}_{3}{ }^{-}$as an interlayer anion of $\mathrm{Zn} / \mathrm{Al}-\mathrm{NO}_{3}$. This peak was completely removed from ZEB nanocomposite as the intercalation of anions B4 and EUS has taken place.

FTIR spectra of pure B4 show peaks at $1,200 \mathrm{~cm}^{-1}$ (symmetric) and 1,029 $\mathrm{cm}^{-1}$ (asymmetric), stretching of $\mathrm{SO}_{3}^{-}$group, $1,596 \mathrm{~cm}^{-1}, 1,490 \mathrm{~cm}^{-1}$, and $1,446 \mathrm{~cm}^{-1}$ for $\mathrm{C}=\mathrm{C}$ vibrations of aromatic ring, $1,379 \mathrm{~cm}^{-1}$ (in plane deformation vibration of $\left.\mathrm{CH}_{3}\right), 1,352 \mathrm{~cm}^{-1}\left(\mathrm{R}-\mathrm{SO}_{2}-\mathrm{OH}\right.$ stretch), and $1,270 \mathrm{~cm}^{-1}\left(\mathrm{Ar}-\mathrm{O}-\mathrm{CH}_{3}\right)$. The FTIR spectra of pure EUS show peaks at $1,567 \mathrm{~cm}^{-1}, 1,497 \mathrm{~cm}^{-1}$, and $1,455 \mathrm{~cm}^{-1}$ for $\mathrm{C}=\mathrm{C}$ vibrations of aromatic ring, $1,368 \mathrm{~cm}^{-1}$ ( $\mathrm{R}-\mathrm{SO}_{2}-\mathrm{OH}$ stretch), $1,226 \mathrm{~cm}^{-1}$, and $1,177 \mathrm{~cm}^{-1}(\mathrm{C}=\mathrm{N}$ stretch $), 3,425 \mathrm{~cm}^{-1}(\mathrm{~N}-\mathrm{H}$ stretching), and $1,629 \mathrm{~cm}^{-1}(\mathrm{~N}-\mathrm{H}$ bending). Due to the intense

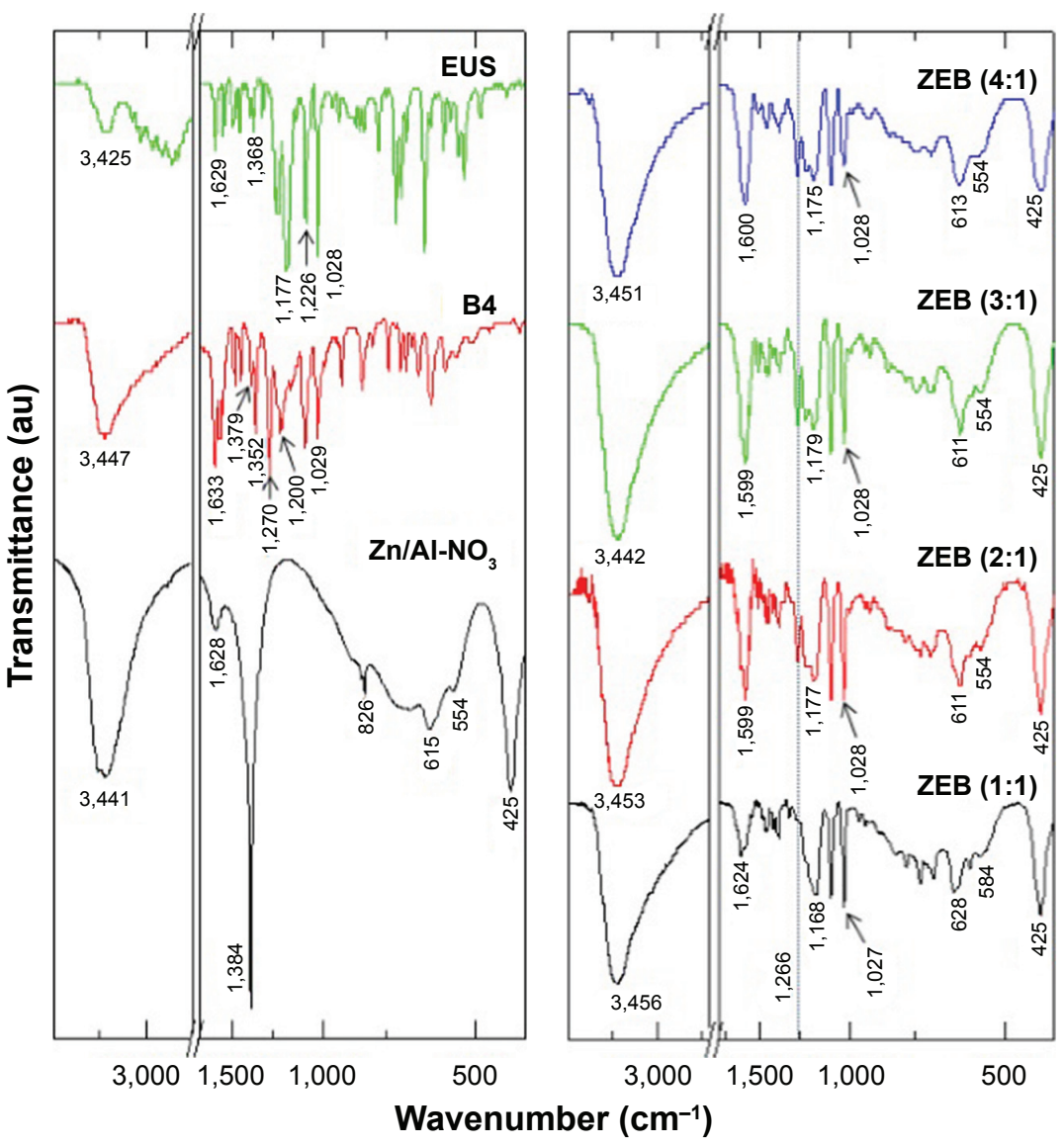

Figure 4 FTIR spectra of Zn/AI-NO , B4, EUS, and dual-guest intercalated products; ZEB (I:I), ZEB (2:I), ZEB (3:I), and ZEB (4:I). Abbreviations: B4, benzophenone 4; EUS, Eusolex ${ }^{\circledR}$ 232; FTIR, Fourier transform infrared; ZEB, dual-guest nanocomposite synthesized with B4 and EUS. 
vibration of a $\mathrm{C}=\mathrm{N}$ stretching at around $1,200 \mathrm{~cm}^{-1}$ range, only asymmetric vibration band of sulfonate group could be detected at $1,028 \mathrm{~cm}^{-1}$.

When equal molar concentration was used, B4 failed to intercalate in a substantial amount. This was evident in the FTIR spectra of dual-guest nanocomposite as no observation of vibration band that could be assigned to $\mathrm{O}-\mathrm{CH}_{3}$ was detected at $1,600 \mathrm{~cm}^{-1}$ (attributing to B4) for the ZEB (1:1) sample. Instead, a broad peak centered at $1,624 \mathrm{~cm}^{-1}$ was detected, a characteristic of N-H bending of EUS. This is in accordance with high preference intercalation by EUS as shown by the UV-VIS analysis (Table 3). Successful intercalation of B4 was confirmed with the presence of Ar-O- $\mathrm{CH}_{3}$ stretching at $1,266 \mathrm{~cm}^{-1}$ for samples ZEB (2:1), ZEB (3:1), and ZEB (4:1). This nanocomposite exhibits most of the vibrational bands that can be assigned to respective guests. However, several vibrations were shifted due to interaction between guest anions and the interlayer. Absorption band corresponding to $\mathrm{R}-\mathrm{SO}_{2}-\mathrm{OH}$ was not observed after intercalation due to immobilization of sulfoxylic guests within the LDH host.

\section{Thermal analysis}

TGA/DTG measurement of B4, EUS, Zn/Al-NO, and dualguest ZEB (3:1) nanocomposites are shown in Figure 5.

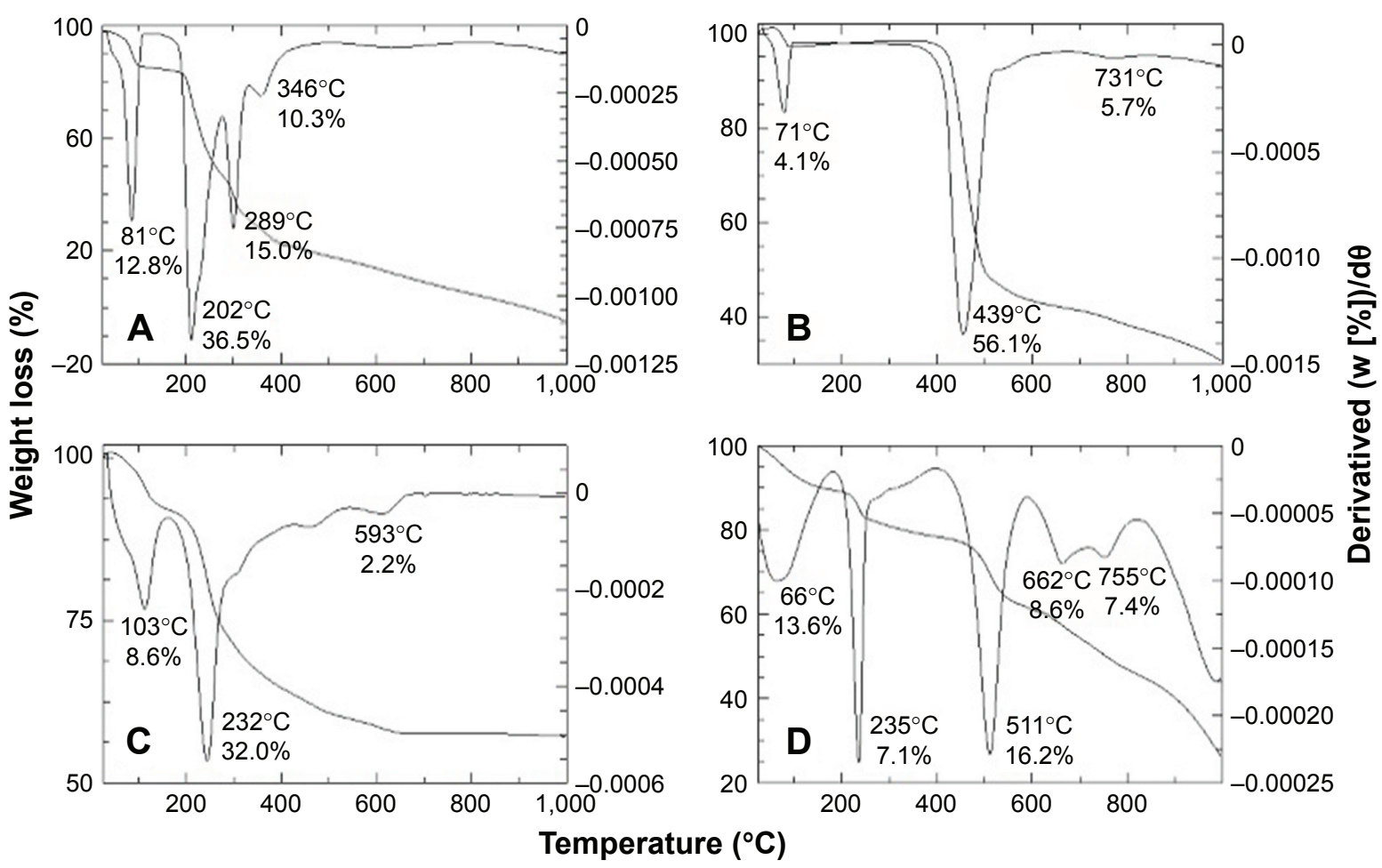

Figure 5 TGA/DTG analyses of B4 (A), EUS (B), Zn/AI-NO $(\mathbf{C})$, and dual-guest nanocomposite ZEB (3:I) (D).

Abbreviations: B4, benzophenone 4; EUS, Eusolex ${ }^{\circledR} 232$; TGA/DTG, thermogravimetric and differential thermogravimetric analyses; ZEB (3:I), dual-guest nanocomposite synthesized with B4:EUS molar ratio 3:1.

TGA/DTG thermograms exhibit the thermal decomposition behavior of samples.

Thermal decomposition of UV absorber B4 occurs in four stages. The first at the maximum temperature $81{ }^{\circ} \mathrm{C}$ is most probably due to the removal of moisture in the sample. The rest of the stages can be attributed to decomposition and combustion of the organic compound up until the maximum temperature of $350^{\circ} \mathrm{C}$. Pure B4 did not completely decompose at temperature until $1,000^{\circ} \mathrm{C}$.

Thermal decomposition profile of EUS shows three main events. The first one corresponds to the removal of moisture and the subsequent stages correspond to decomposition and combustion of organic matter. However not all compounds were decomposed, as DTG curve showed weight loss peak coming up after $450^{\circ} \mathrm{C}$ and continuing above our analysis condition limit.

TGA/DTG curves of $\mathrm{Zn} / \mathrm{Al}^{-\mathrm{NO}_{3}} \mathrm{LDH}$ in Figure $5 \mathrm{C}$ show three weight loss stages. The first event is attributed to loss of physisorbed and interlayer water molecules. The second and most prominent peak corresponds to dehydroxylation of LDH matrix, while the last step is linked to decomposition of intercalated nitrates. ${ }^{31}$ Thermal decomposition eventually reached completion at around $680^{\circ} \mathrm{C}$.

Dual-guest nanocomposite ZEB (3:1) showed characteristic decomposition peaks of LDHs with its first two 

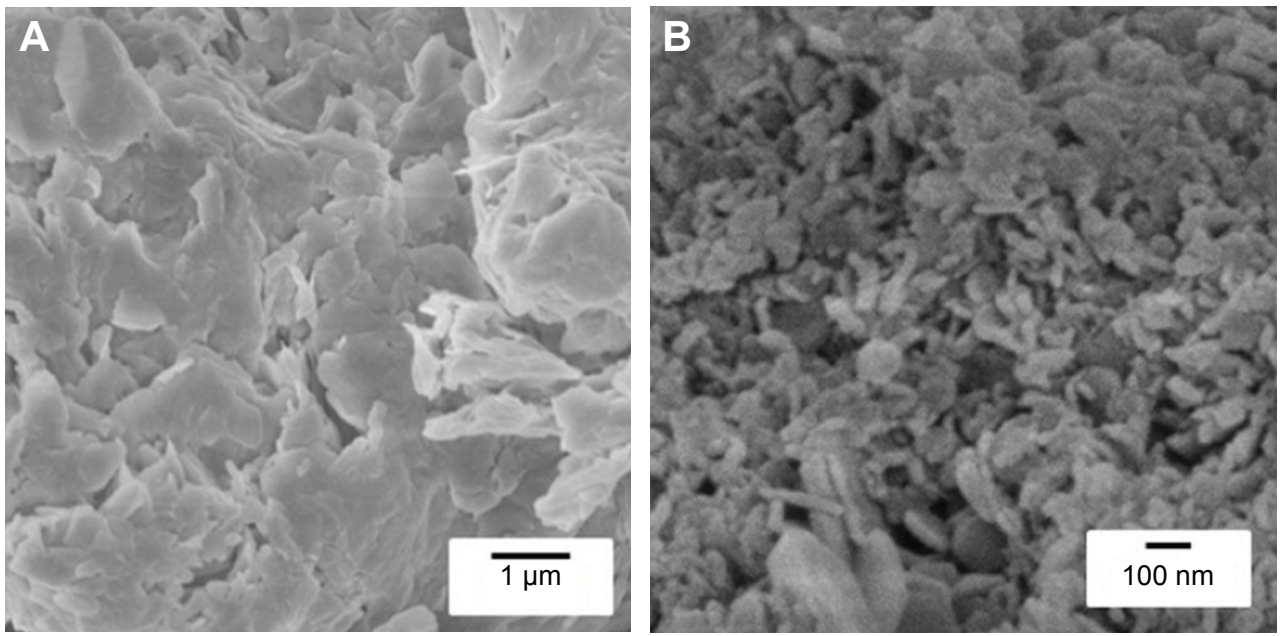

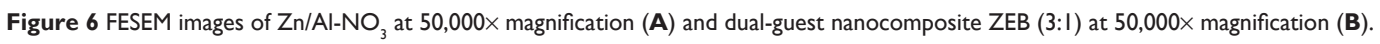

Abbreviations: B4, benzophenone 4; EUS, Eusolex ${ }^{\circledR}$ 232; FESEM, field electron scanning electron microscopy; ZEB (3:I), dual-guest nanocomposite synthesized with B4:EUS molar ratio 3:1.

weight loss events. Subsequent weight loss events centered at 511,662 , and $755^{\circ} \mathrm{C}$ are attributed to the decomposition of intercalated organic species. It should be noted that the thermal decomposition region of dual-guest nanocomposite is significantly higher than pure B4 and EUS. This indicates that the thermal stability is enhanced due to interaction between B4 and EUS and the layered structure.

\section{Surface morphology}

FESEM images of $\mathrm{Zn} / \mathrm{Al}^{-\mathrm{NO}_{3}}$ and dual-guest ZEB (3:1) nanocomposite are shown in Figure 6.

Pristine $\mathrm{Zn} / \mathrm{Al}^{-\mathrm{NO}_{3}}$ consisted of agglomerates of very thin nonuniform plate particles with sharp edges. Single intercalation of EUS and B4 reported morphologies of plate-like structures with blunt edges. The former showed 50-500 nm in size, while the latter showed smaller sizes (ca. 25-100 nm). Dual-guest nanocomposite, ZEB (3:1) showed a morphology similar to that of $\mathrm{Zn} / \mathrm{Al}-\mathrm{B} 4$ but with less agglomeration and sizes ranging from 20 to $<100 \mathrm{~nm}$. Furthermore, the dual-guest nanocomposite exhibited an increase in particle thickness compared to the pristine LDH.

Figure 7 shows the nitrogen adsorption-desorption isotherms of $\mathrm{Zn} / \mathrm{Al}^{-\mathrm{NO}_{3}}$ and dual-guest $\mathrm{ZEB}$ nanocomposites. The nanocomposites depict Type IV isotherm by the International Union of Pure and Applied Chemistry (IUPAC) classification. ${ }^{32}$ According to IUPAC classification, the type of hysteresis loop for these nanocomposites can be classified as H3-type hysteresis loop. This type of loop is typical for mesoporous materials comprised of agglomerates of platelike particles with slit-shaped pores.

Figure 8 shows the Barrett-Joyner-Halenda method (BJH) desorption pore size distribution for $\mathrm{Zn} / \mathrm{Al}-\mathrm{NO}_{3}$ and dual-guest nanocomposite ZEB (3:1). Pore size distribution showed a wide distribution of pore diameter for pristine $\mathrm{Zn} / \mathrm{Al}-\mathrm{NO}_{3}$ (inset). On the other hand, dual-guest nanocomposite, ZEB (3:1) (outset), showed a single-peaked pore diameter distribution centered at $245 \AA$.

A summary of Brunauer, Emmett, and Teller method surface area, BJH pore volume, and BJH pore diameter for the nanocomposites is given in Table 4.

Varying wideness of desorption branch of the hysteresis loop and pore diameter suggests different pore texture as a result of LDH gallery occupation by different guest anions.

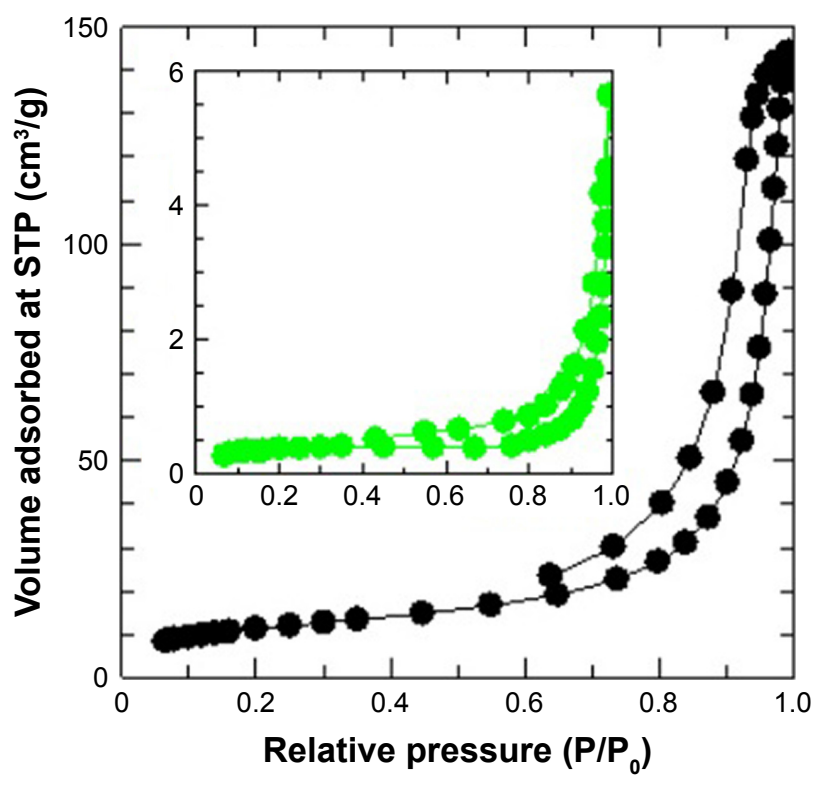

Figure 7 Adsorption-desorption isotherms of $\mathrm{Zn} / \mathrm{Al}-\mathrm{NO}_{3}$ (inset) and dual-guest nanocomposite ZEB (3:1).

Abbreviations: B4, benzophenone 4; EUS, Eusolex ${ }^{\circledR}$ 232; STP, standard temperature and pressure; ZEB (3:I), dual-guest nanocomposite synthesized with B4:EUS molar ratio 3:1. 


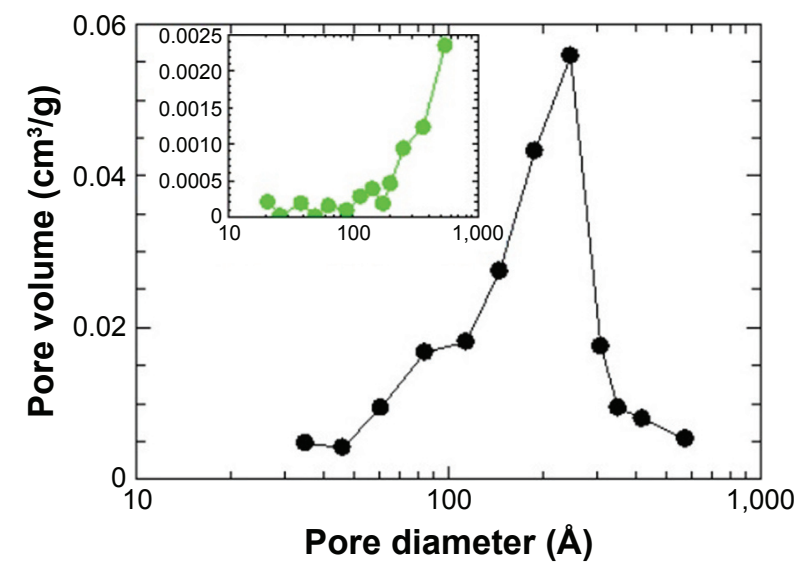

Figure $8 \mathrm{BJH}$ pore size distribution of $\mathrm{Zn} / \mathrm{Al}-\mathrm{NO}_{3}$ (inset) and dual-guest nanocomposite ZEB prepared at B4:EUS =3:I.

Abbreviations: B4, benzophenone 4; BJH, Barrett-Joyner-Halenda; EUS, Eusolex ${ }^{\circledR}$ 232; ZEB (3:I), dual-guest nanocomposite synthesized with B4:EUS molar ratio 3:1.

\section{UV ray absorption ability analysis}

Solid-state absorbance spectra of B4, EUS, Zn/Al- $\mathrm{NO}_{3}-\mathrm{LDH}$, and dual-guest nanocomposites are shown in Figure 9.

B4 showed a strong ability to absorb both UVB (280-320 nm) and UVA (320-400 nm), while EUS showed a weak ability to absorb short UVA. UVA absorption ability of B4 was superior to that of EUS. This is due to the substituent of aromatic ring in $\mathrm{B} 4$, the methoxy group, and the hydroxy group. ${ }^{33} \mathrm{UV}$ absorption ability of pristine $\mathrm{Zn} / \mathrm{Al}-\mathrm{NO}_{3}$ $\mathrm{LDH}$ was shown to be poor. UV absorption peak at $300 \mathrm{~nm}$ for $\mathrm{Zn} / \mathrm{Al}-\mathrm{NO}_{3}$ is ascribed to the presence of $\mathrm{NO}_{3}{ }^{-}$in $\mathrm{LDH}$ interlayer. ${ }^{34}$

However, as a result of intercalation with UV ray absorbing molecules, LDH nanocomposites exhibit broad and strong UV-shielding capability that mimics intercalated compound. This is an indication that the inorganic lattice retains UV absorbent molecules and attains chromophores that influence absorption characteristic of those molecules. The effect of broadened absorption range is due to spatial confinement and host-guest interactions, namely electrostatic attraction, hydrogen bonding, and van der Waals forces.

The dual-guest nanocomposite experienced an absorption peak shift to the higher wavelength region, also known as

Table 4 Surface properties of $\mathrm{Zn} / \mathrm{Al}-\mathrm{NO}_{3}$ and ZEB (3:I) nanocomposites

\begin{tabular}{llll}
\hline Sample & $\begin{array}{l}\text { BET surface } \\
\text { area }\left(\mathrm{m}^{2} / \mathbf{g}\right)\end{array}$ & $\begin{array}{l}\text { BJH pore } \\
\text { volume }\left(\mathrm{m}^{2} / \mathbf{g}\right)\end{array}$ & $\begin{array}{l}\text { BJH pore } \\
\text { diameter }(\mathbf{A})\end{array}$ \\
\hline $\mathrm{Zn} / \mathrm{Al}-\mathrm{NO}_{3}$ & $\mathrm{I}$ & 0.01 & 166 \\
$\mathrm{ZEB}(3: \mathrm{l})$ & $4 \mathrm{I}$ & 0.22 & 147 \\
\hline
\end{tabular}

Abbreviation: BET, Brunauer, Emmett, and Teller method; BJH, Barrett-JoynerHalenda method; ZEB (3:I), dual-guest nanocomposite synthesized with B4:EUS molar ratio $3: 1$. red shift, which happened as a result of edge-to-edge arrangement of intercalated B4 and EUS molecules (Figure 2C) when electron-donating groups $-\mathrm{OCH}_{3}$ and $-\mathrm{OH}$ induced conjugation..$^{35} \mathrm{UV}$ absorption spectrum of dual-guest nanocomposites showed that the ratio of guest anions intercalated does not impart a significant effect on absorption range or intensity. ZEB nanocomposites maintained a broad and intense absorption similar to that of the organic UV absorbent, B4. A slight decrease in absorption ability in comparison to B4 can be attributed to the dilution effect of intercalation in LDH host. UV rays in sunlight which reach the ground are mainly UVA (90\%-99\%) and UVB $(1 \%-10 \%) .{ }^{36}$ Therefore, a shift to the UVA range as observed is preferable for higher protection against the sun. Although B4 loading was not detected in the ZEB (1:1) sample by FTIR and UV-VIS spectrometer, solid-state absorbance spectrum of ZEB (1:1) showed broad absorbance that is more similar to B4 intercalation rather than EUS. Thus, it may be possible that intercalation and surface absorption of B4 had occurred at a negligible amount that could not be detected by FTIR or UV-VIS spectrometer.

UV absorption spectrum corresponds to electron excitation from valence band to conduction band. The spectrum can be used to determine the band gap values using the Kubelka-Munk equation: ${ }^{37}$

$$
(\mathrm{F} \cdot \mathrm{h} v)^{2}=\mathrm{A}\left(\mathrm{h} v-\mathrm{E}_{\mathrm{g}}\right)
$$

where $\mathrm{F}$ is the Kubelka-Munk, $\mathrm{h}$ is Planck's constant, A is a proportionality constant, $h v$ is the photon energy, and $\mathrm{E}_{\mathrm{g}}$ is the band gap energy. Band gap values were extracted by

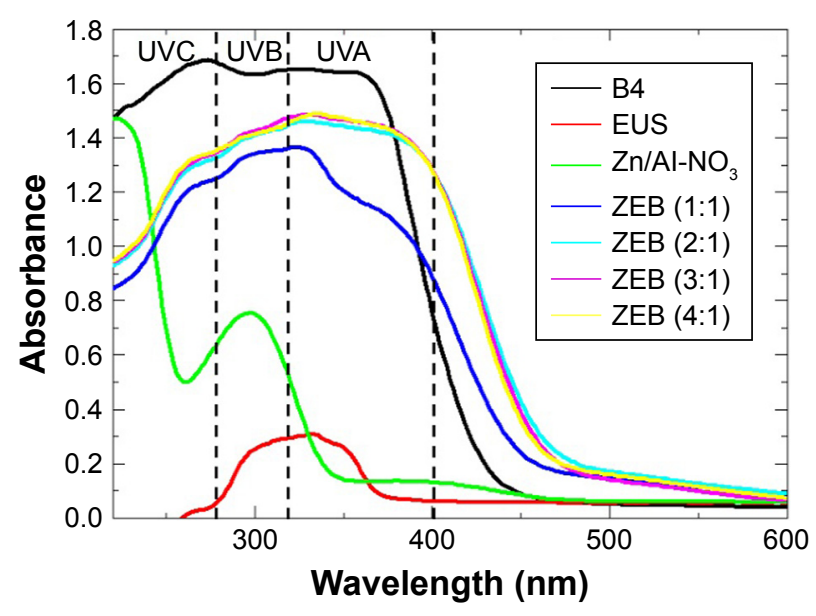

Figure 9 Solid-state absorbance spectra of B4, EUS, $\mathrm{Zn} / \mathrm{Al}-\mathrm{NO}_{3}$, and dual-guest intercalated products; ZEB (I:I), ZEB (2:I), ZEB (3:I), and ZEB (4:I).

Abbreviations: B4, benzophenone 4; EUS, Eusolex ${ }^{\circledR} 232$; ZEB, dual-guest nanocomposite synthesized with B4 and EUS. 


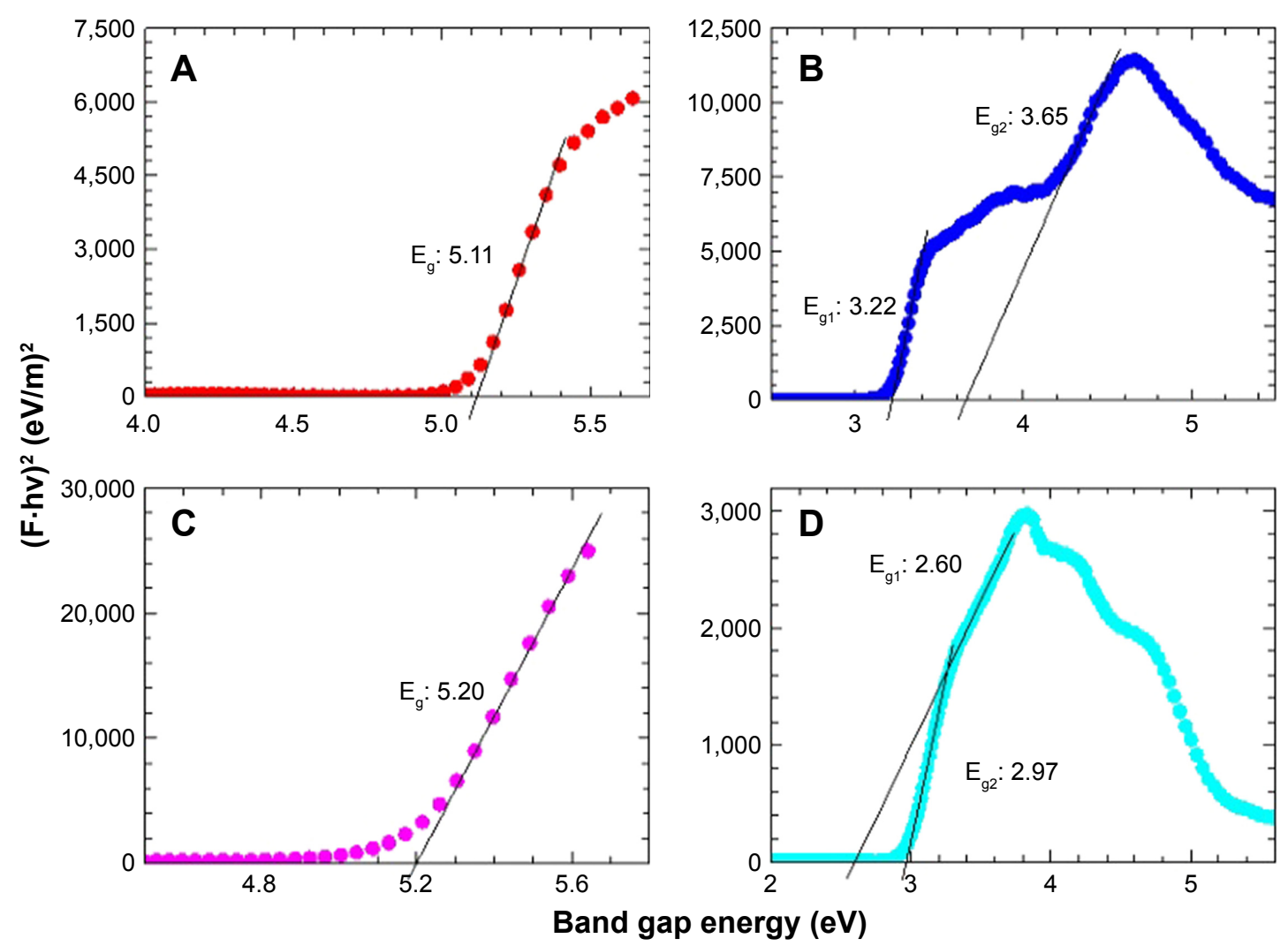

Figure 10 Kubelka-Munk transformed reflectance spectra of Zn/AI-NO $(\mathbf{A})$, B4 (B), EUS (C), and dual-guest intercalated product; ZEB (3:I) (D). Abbreviations: B4, benzophenone 4; EUS, Eusolex ${ }^{\circledR}$ 232; ZEB (3:1), dual-guest nanocomposite synthesized with B4:EUS molar ratio 3:I.

plotting Eq 3 as $(\mathrm{F} \cdot \mathrm{hv})^{2}$ against $\mathrm{h} v$ and extrapolating the linear region straight line to the hv intercept. Band gaps of B4, EUS, $\mathrm{Zn} / \mathrm{Al}-\mathrm{NO}_{3}$, and dual-guest nanocomposite $\mathrm{ZEB}$ (3:1) were investigated by these measurements, as shown in Figure 10.

Pristine $\mathrm{Zn} / \mathrm{Al}-\mathrm{NO}_{3}$ showed a single band gap at $5.11 \mathrm{eV}$. B4 exhibited band gaps at 3.22 and $3.65 \mathrm{eV}$, while EUS exhibited a single band gap at $5.20 \mathrm{eV}$. Dual-guest nanocomposites ZEB (3:1) exhibited a shift to narrower band gap values, 2.60 and $2.97 \mathrm{eV}$. A narrower band gap value accounts for its high visible-light photocatalytic availability. ${ }^{38}$ It is generally known that high photocatalytic activity is brought upon by high specific surface area. ${ }^{39}$ Thus, we could attribute the shift to narrower band gap value to the specific surface area increase pattern, as discussed in the "Surface morphology" section.

\section{Retention of sunscreen molecules in dual-guest nanocomposites}

Interlayer anions of LDH are held by weak electrostatic attraction and can be exchanged with anions of higher affinity to the layered host. Retention of organic sunscreen molecules in LDH matrices was studied in a release medium of $0.5 \mathrm{~mol} / \mathrm{L} \mathrm{NaCl}$ (Figure 11A) and $\mathrm{pH} 5.5$ phosphate buffer (Figure 11B) using a dual-guest sample prepared at B4:EUS $=3: 1$. ZEB (3:1) nanocomposite was selected as it contains almost equal percentage of intercalated anion. Respective release media were chosen in order to simulate the application condition of the new sunscreen formulation. $0.5 \mathrm{~mol} / \mathrm{L} \mathrm{NaCl}$ represented artificial sea water, while $\mathrm{pH} 5.5$ phosphate buffer reproduced skin $\mathrm{pH}$ condition.

The release profiles showed that accumulated release was rapid for the first 4 hours of contact with $\mathrm{pH} 5.5$ phosphate buffer. Then, the release slowed down until equilibrium was achieved of about $73.65 \%$ and $65.98 \%$ for B4 and EUS, respectively, after 1,250 minutes (roughly 20 hours). Similarly, in the case of artificial sea water, for the first 2,000 minutes, rapid release was observed. The release was progressively slower after that and achieved a maximum accumulated release of $61.86 \%$ and $58.24 \%$ for B4 and EUS, respectively, after almost 7 days in artificial sea water. It was predetermined that sample ZEB prepared at B4:EUS $=3: 1$ contained a larger amount of intercalated B4. Therefore, higher release of B4 than EUS is expected.

Although the release of sunscreen molecules from the formulation was observed, the results demonstrated that 

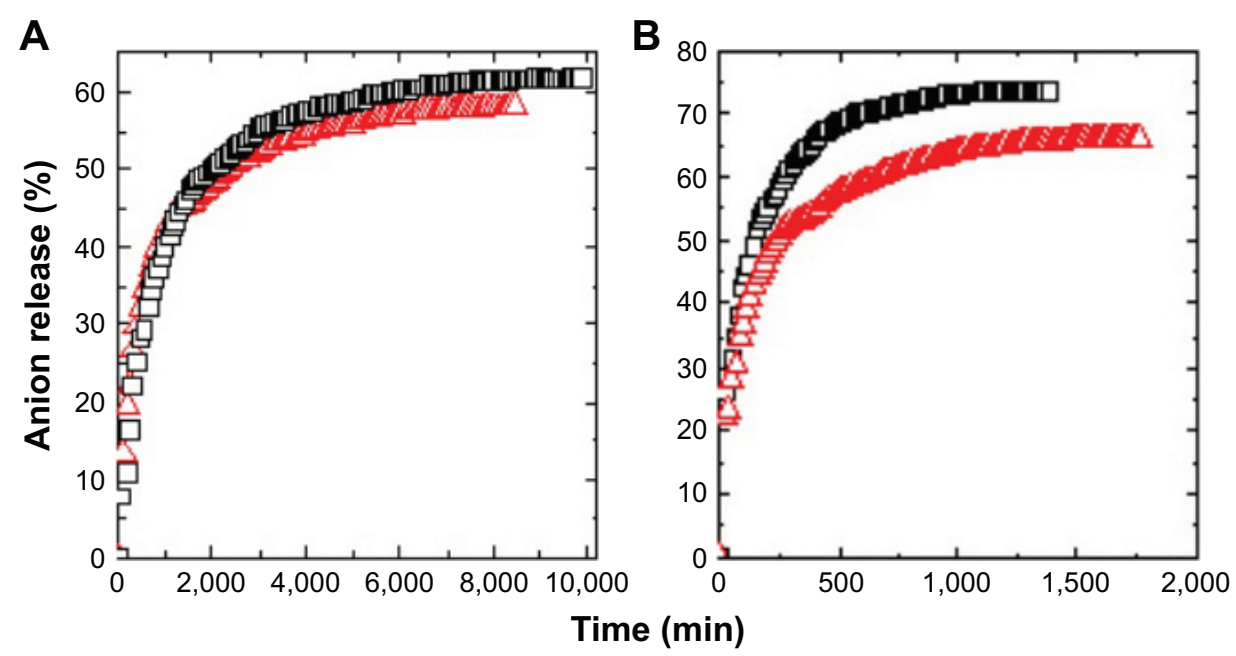

Figure I I Controlled release of B4 $(\square)$ and EUS $(\triangle)$ from dual-guest nanocomposite ZEB (3:I) in $0.5 \mathrm{~mol} / \mathrm{L} \mathrm{NaCl}(\mathbf{A})$ and pH 5.5 phosphate buffer solution (B). Abbreviations: B4, benzophenone 4; EUS, Eusolex ${ }^{\circledR}$ 232; ZEB (3:I), dual-guest nanocomposite synthesized with B4:EUS molar ratio 3:I.

direct contact of sunscreen molecules with skin could be reduced with inhibition of UV absorbents in the LDH host. Furthermore, the inorganic metal layer extended UV protection compared to pure sunscreen compounds. This was achieved by retention in host and eventually slowing down of the exposure of sunscreen molecules to photodegradable conditions.

\section{Release kinetics of EUS and B4 from ZEB nanocomposite}

Kinetic release of UV absorbing anions from ZEB (3:1) nanocomposite was investigated by fitting the release profiles of the EUS and B4 into the following kinetic models; zeroth(Eq 4) ${ }^{40}$ first- (Eq 5), ${ }^{41}$ pseudo-second order kinetics (Eq 6), ${ }^{42}$ and parabolic diffusion (Eq 7). ${ }^{43}$ The equations are expressed below, where $c$ is a constant, and $C_{e q}$ and $C_{t}$ are the concentration of anion at equilibrium and time $t$, respectively.

$$
\begin{gathered}
C_{t}=k t+C_{o} \\
-\log \left(1-C_{t}\right)=k t \\
t / C_{t}=1 / k_{2} C_{e q}{ }^{2}+\left(1 / C_{e q}\right) t \\
C_{t} / C_{e q}=c+k t^{0.5}
\end{gathered}
$$

The fitting results are shown in Figure 12. Correlation coefficient values for all kinetic models are summarized in Table 5.

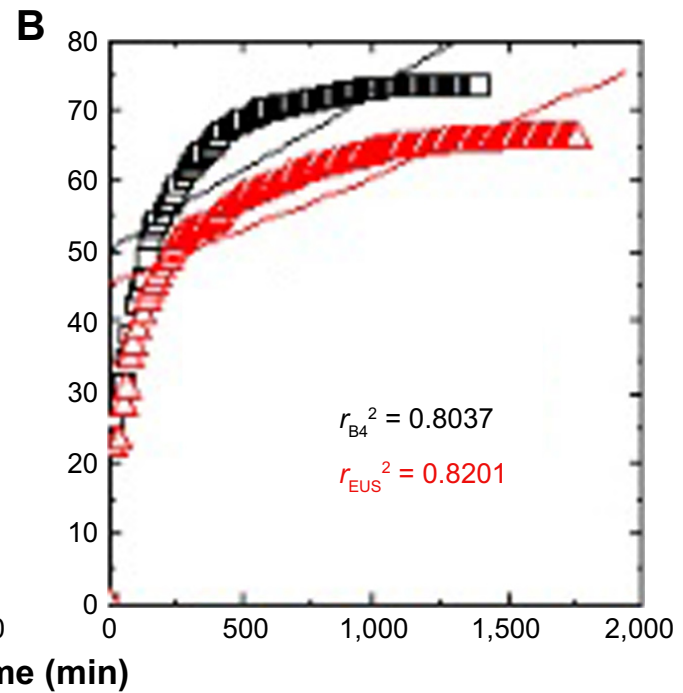

Figure 12 (Continued) 

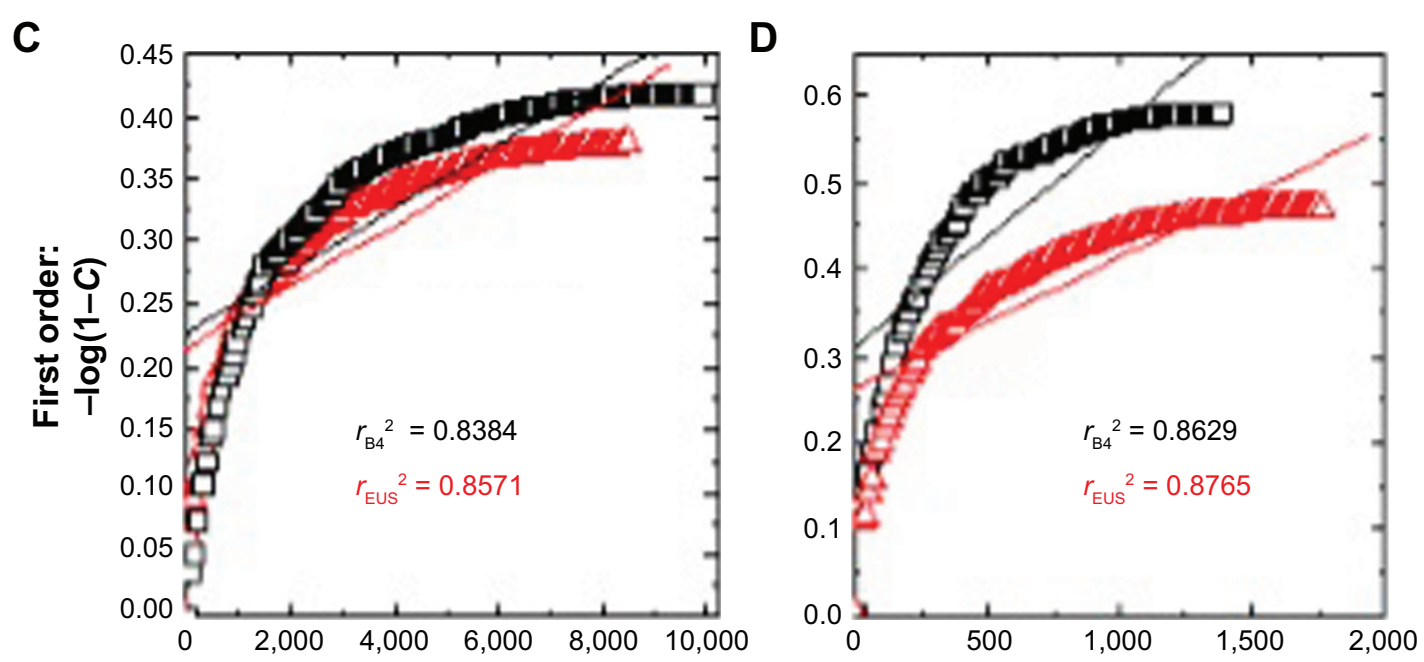

Time (min)

E

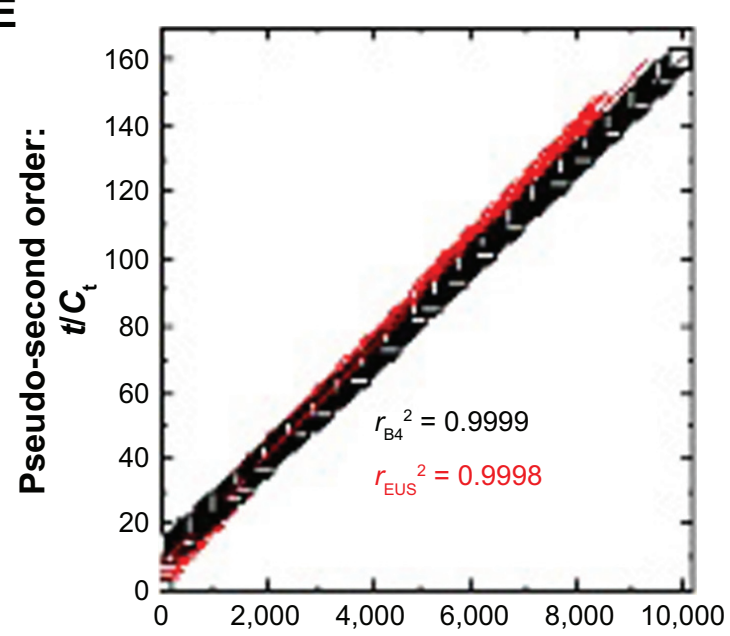

$\mathbf{F}$

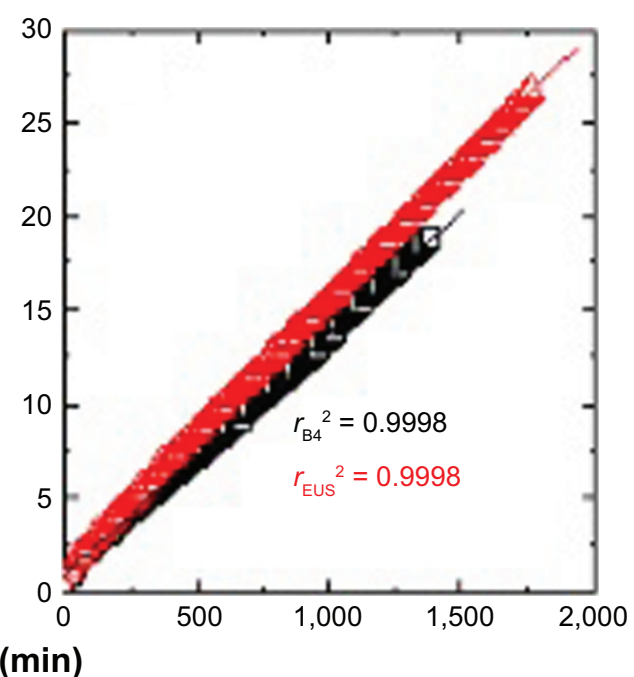

G

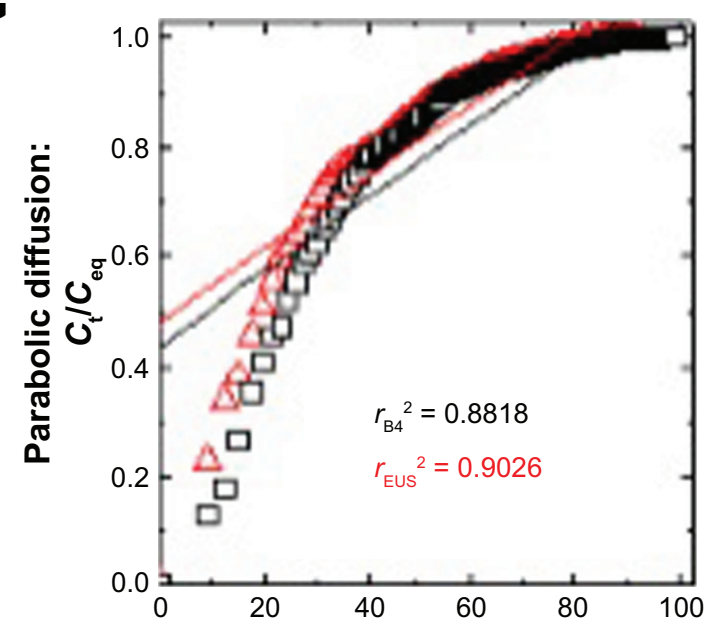

$\mathrm{H}$

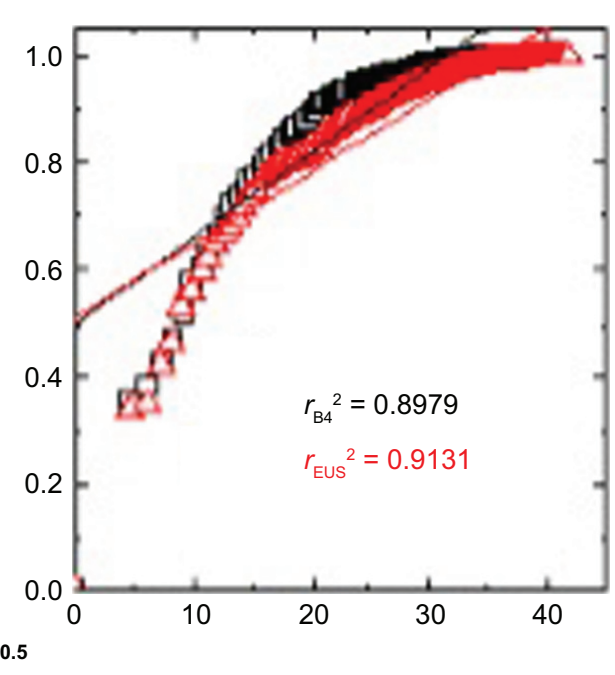

Figure 12 Fitting the data release of B4 $(\square)$ and EUS $(\triangle)$ from dual-guest nanocomposite ZEB (3:I) into media for zeroth-, first-, pseudo-second order, and parabolic diffusion kinetics for $0.5 \mathrm{~mol} / \mathrm{L} \mathrm{NaCl}(\mathbf{A}, \mathbf{C}, \mathbf{E}$, and $\mathbf{G}$, respectively) and $\mathrm{pH} 5.5$ phosphate buffer solution $(\mathbf{B}, \mathbf{D}, \mathbf{F}$, and $\mathbf{H}$, respectively).

Abbreviations: B4, benzophenone 4; EUS, Eusolex ${ }^{\circledR}$ 232; ZEB (3:I), dual-guest nanocomposite synthesized with B4:EUS molar ratio 3:I. 
Table 5 Correlation coefficient, rate constant, and half time obtained by fitting the release data of B4 and EUS from ZEB (3:I) into various media using zeroth-, first-, pseudo-second order, and parabolic diffusion kinetic models

\begin{tabular}{|c|c|c|c|c|c|c|c|}
\hline \multirow[t]{2}{*}{ Media } & \multirow{2}{*}{$\begin{array}{l}\text { Saturated } \\
\text { release (\%) }\end{array}$} & \multicolumn{4}{|c|}{ Correlation coefficient, $r^{2}$} & \multirow{2}{*}{$\begin{array}{l}\text { Rate constant of } \\
\text { pseudo-second order, } \\
k\left(\mathrm{~L} \mathrm{mg}^{-1} \mathrm{~min}^{-1}\right)\end{array}$} & \multirow{2}{*}{$\begin{array}{l}t_{1 / 2} \text { of pseudo- } \\
\text { second order } \\
\text { (min) }\end{array}$} \\
\hline & & $\begin{array}{l}\text { Zeroth } \\
\text { order }\end{array}$ & $\begin{array}{l}\text { First } \\
\text { order }\end{array}$ & $\begin{array}{l}\text { Pseudo- } \\
\text { second order }\end{array}$ & $\begin{array}{l}\text { Parabolic } \\
\text { diffusion }\end{array}$ & & \\
\hline \multicolumn{8}{|l|}{ B4 release } \\
\hline $0.5 \mathrm{~mol} / \mathrm{L} \mathrm{NaCl}$ & 61.86 & 0.7751 & 0.8384 & 0.9999 & 0.8818 & $2.44 \times 10^{-5}$ & 619 \\
\hline Phosphate buffer $\mathrm{pH} 5.5$ & 73.65 & 0.7993 & 0.8629 & 0.9998 & 0.8979 & $1.70 \times 10^{-4}$ & 75 \\
\hline \multicolumn{8}{|l|}{ EUS release } \\
\hline $0.5 \mathrm{~mol} / \mathrm{L} \mathrm{NaCl}$ & 58.24 & 0.8037 & 0.8571 & 0.9998 & 0.9026 & $3.40 \times 10^{-5}$ & 479 \\
\hline Phosphate buffer pH 5.5 & 65.98 & 0.8201 & 0.8765 & 0.9998 & 0.9131 & $1.47 \times 10^{-4}$ & 98 \\
\hline
\end{tabular}

Notes: Zeroth order: $C_{t}=k t+c$, first order: $-\log (\mathrm{I}-C)=k t+c$, pseudo-second order: $t / C_{t}=I / k_{2} C_{\text {eq }}{ }^{2}+\left(I / C_{\text {eq }}\right) t$, parabolic diffusion: $C_{t} / C_{\text {eq }}=c+k t^{0.5}, c=a$ constant; $C_{e q}=$ concentration of anion at equilibrium; $C_{t}=$ concentration of anion at time $t$.

Abbreviations: B4, benzophenone 4; EUS, Eusolex ${ }^{\circledR}$ 232; ZEB (3:I), dual-guest nanocomposite synthesized with B4:EUS molar ratio 3:I.

By comparing the correlation coefficient values, we found that the release patterns of EUS and B4 anions from LDH host best fit the pseudo-second order kinetic.

Using the pseudo-second order equation, we could calculate the $t_{1 / 2}$ value. $t_{1 / 2}$ is defined as time taken for the release to be half of the accumulated release. $t_{1 / 2}$ values for release in $\mathrm{pH} 5.5$ phosphate buffer solution were 75 and $98 \mathrm{~min}$ for B4 and EUS release, respectively. On the other hand, $t_{1 / 2}$ values for release in $0.5 \mathrm{~mol} / \mathrm{L} \mathrm{NaCl}$ were 619 and 479 min for B4 and EUS, respectively. Release rate constant, $k$, quantifies the speed of anion release. As can be seen in Table 5, the rate constants for release in skin $\mathrm{pH}$ condition are $2.44 \times 10^{-5}$ and $3.40 \times 10^{-5} \mathrm{~L} \mathrm{mg}^{-1} \mathrm{~min}^{-1}$ for B4 and EUS anions, respectively. In artificial seawater, the rate constants are $1.70 \times 10^{-4}$ and $1.47 \times 10^{-4} \mathrm{~L} \mathrm{mg}^{-1} \mathrm{~min}^{-1}$ for B4 and EUS anions, respectively.

Higher $t_{1 / 2}$ value and lower $k$ value indicate slower release of the anion from the LDH interlayer. As supported by $t_{1 / 2}$ and $k$ values, anion release under skin $\mathrm{pH}$ condition was significantly faster than artificial seawater. This can be explained by the slight dissolution of LDH under a slightly acidic condition. ${ }^{44}$ Moreover, the presence of phosphate combined with other anions in phosphate buffer solution induces multiple hydrolysis of phosphate and speeds up the ion-exchange process. ${ }^{45,46}$ Slower release in $0.5 \mathrm{~mol} / \mathrm{L}$ $\mathrm{NaCl}$ was attributed to the low ion-exchange affinity of the incoming anion, chloride, toward the interlayer gallery of $\mathrm{LDH}^{47}$

\section{Cytotoxicity induction on HDF cells}

Cytotoxicity induced by the nanocomposite and test compounds on HDF cells was investigated by cell viability assays. HDF cells were exposed to the LDH nanocomposites B4 and EUS at the concentrations of 1.562, 3.125, 6.25, 12.5, 25, and $50 \mu \mathrm{g} / \mathrm{mL}$ for $24 \mathrm{~h}$ and cell viabilities were determined by MTT assay. The cytotoxicity findings have shown that pristine $\mathrm{Zn} / \mathrm{Al}-\mathrm{NO}_{3}-\mathrm{LDH}$, pure guest, B4 and EUS, as well as dual-guest nanocomposite ZEB (3:1) up to the test concentration of $25 \mu \mathrm{g} / \mathrm{mL}$ did not produce any significant cytotoxicity to HDF cells. Irrespective of intercalation of two active agents of sunscreen into the LDH matrix, the dual-guest nanocomposite maintained a nontoxic nature up to $25 \mu \mathrm{g} / \mathrm{mL}$. As the concentrations of all samples were increased to $50 \mu \mathrm{g} / \mathrm{mL}$, cytotoxicity was observed to significantly increase (Figure 13).

Therefore, we concluded that the cytotoxicity of samples acted in a dose-dependent manner. Based on this fruitful investigation, we will use the nontoxic concentration of the dual-guest nanocomposites for further therapeutic investigations.

\section{Conclusion}

The present study was designed to determine the effect of simultaneous intercalation of UV ray absorbent agents in $\mathrm{Zn} / \mathrm{Al}-\mathrm{LDH}$ on its resulting properties. It was discovered that using equimolar concentrations of B4 and EUS intercalation selectivity is favorable to EUS. Based on the results presented, we have demonstrated that this selectivity is tuneable by changing the molar ratio of the guests during the synthesis. We could manipulate this nature to ration out guests, and thus produce nanocomposites of customized composition. Dual-guest nanocomposites combined showed excellent absorption capacity in the UV region of both guest anions while the inorganic host improved thermal stability, broadened UV absorptivity range, and provided retention of photodegradable organic UV ray absorbing molecules. The cytotoxicity study of dualguest nanocomposites ZEB (3:1) on dermal cells showed no significant toxicity up to $25 \mu \mathrm{g} / \mathrm{mL}$. However, further therapeutic study is required to shed light on the toxicity 


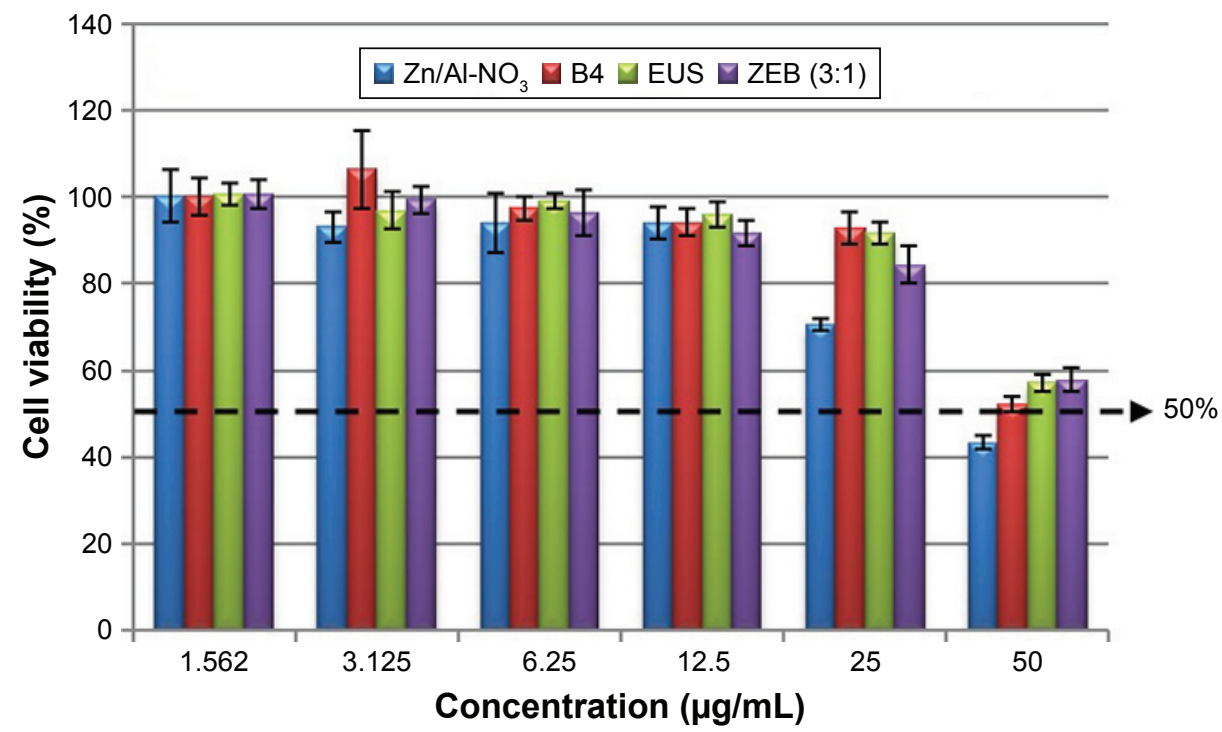

Figure I 3 Concentration-response curves obtained by plotting the percentage of viability of HDF cells exposed to B4, EUS, nanocomposite ZEB (3:I), and Zn/AI-NO for 24 hours.

Note: Results are presented as mean \pm SD of triplicate values.

Abbreviations: B4, benzophenone 4; EUS, Eusolex ${ }^{\circledR}$ 232; HDF, human dermal fibroblast; ZEB, dual-guest nanocomposite synthesized with B4:EUS molar ratio 3:I.

mechanism of LDH nanocomposite on dermal cells. Even though the intercalated guest could be released from LDH host during application on skin via ion exchange, a simulation in sea water and $\mathrm{pH}$ of skin showed a slowing down of exposure of sunscreen molecules to photodegradable conditions. These findings demonstrate the potential for UV ray absorbent guest-intercalated LDHs to be used as a versatile, efficient, and tailor-made sunscreen formulation.

\section{Acknowledgment}

The work was financed by NanoMalaysia Institute for Innovative Technology (NanoMITe) grant under two vot numbers, namely, 9443100 and 5526300 .

\section{Disclosure}

The authors report no conflicts of interest in this work.

\section{References}

1. Xu ZP, Walker TL, Liu K, Cooper HM, Lu GQM, Bartlett PF. Layered double hydroxide nanoparticles as cellular delivery vectors of supercoiled plasmid DNA. Int J Nanomed. 2007;2(2):163-174.

2. Hoyo CD. Layered double hydroxides and human health: An overview. Appl Clay Sci. 2007;36:103-121.

3. Choy J, Choi S, Oh J, Park T. Clay minerals and layered double hydroxides for novel biological applications. Appl Clay Sci. 2007;36(1-3): $122-132$.

4. Hussein MZ, Ali SHA, Zainal Z, Hakim MN. Development of antiproliferative nanohybrid compound with controlled release property using ellagic acid as the active agent. Int J Nanomed. 2011;6:1373-1383.

5. Rives V, del Arco M, Martín C. Layered double hydroxides as drug carriers and for controlled release of non-steroidal anti-inflammatory drugs (NSAIDs): a review. J Control Release. 2013;169(1-2):28-39.
6. Tran HN, Lin CC, Chao HP. Amino acids-intercalated Mg/Al layered double hydroxides as dual-electronic adsorbent for effective removal of cationic and oxyanionic metal ions. Sep Purif Technol. 2018;192: 36-45.

7. Kang H, Kim M, Feng Q, et al. Nanolayered hybrid mediates synergistic co-delivery of ligand and ligation activator for inducing stem cell differentiation and tissue healing. Biomaterials. 2017;149:12-28.

8. Usman MS, Hussein MZ, Fakurazi S, Masarudin MJ, Saad FFA. Gadolinium-doped gallic acid-zinc/aluminium-layered double hydroxide/gold theranostic nanoparticles for a bimodal magnetic resonance imaging and drug delivery system. Nanomaterials (Basel). 2017; 7(9):244.

9. Guan S, Liang R, Li C, Wei M. A supramolecular material for dual-modal imaging and targeted cancer therapy. Talanta. 2017;165:297-303.

10. Guan S, Weng Y, Li M, et al. An NIR-sensitive layered supramolecular nanovehicle for combined dual-modal imaging and synergistic therapy. Nanoscale. 2017;9(29):10367-10374.

11. Sarijo SH, Ghazali SAISM, Hussein MZ. Synthesis of dual herbicidesintercalated hydrotalcite-like nanohybrid compound with simultaneous controlled release property. J Porous Mater. 2015;22(2):473-480.

12. Hussein MZ, Rahman NSSA, Sarijo SH, Zainal Z. Synthesis of a monophasic nanohybrid for a controlled release formulation of two active agents simultaneously. Appl Clay Sci. 2012;58:60-66.

13. Li S, Shen Y, Xiao M, Liu D, Fan L, Zhang Z. Simultaneous intercalation of 1-naphthylacetic acid and indole-3-butyric acid into layered double hydroxides and controlled release properties. J Nanomater. 2014; 2014:1-9.

14. Shi S, Guo F, Xia Y, Su Z, Chen X, Wei M. Preparation of acrylic acid and AMPS cointercalated layered double hydroxide and its application for superabsorbent. J Appl Polymer Sci. 2011;121(3):1661-1668.

15. Lotsch B, Millange F, Walton RI, O'Hare D. Separation of nucleoside monophosphates using preferential anion exchange intercalation in layered double hydroxides. Solid State Sci. 2001;3(8):883-886.

16. Lei L, Khan A, O'hare D. Selective anion-exchange intercalation of isomeric benzoate anions into the layered double hydroxide $\left[\mathrm{LiAl}_{2}(\mathrm{OH})_{6}\right]$ Cl. $\mathrm{H}_{2} \mathrm{O}$. J Solid State Chem. 2005;178(12):3648-3654.

17. Bastien N, Millau J, Rouabhia M, Davies H, Drouin R. The sunscreen agent 2-phenylbenzimidazole-5-sulfonic acid photosensitizes the formation of oxidized guanines in cellulo after UVA or UVB exposure. $J$ Invest Dermatol. 2010;130(10):2463-2471. 
18. Inbaraj JJ, Bilski P, Chignell CF. Photophysical and photochemical studies of 2-phenylbenzimidazole and UVB sunscreen 2-phenylbenzimidazole-5-sulfonic acid. Photochem Photobiol. 2002;75(2):107-116.

19. Hayashi T, Okamoto Y, Ueda K, Kojima N. Formation of estrogenic products from benzophenone after exposure to sunlight. Toxicol Lett. 2006;167(1):1-7.

20. Demirkiran O, Mesaik MA, Beynek H, Abbaskhan A, Choudhary MI. Cellular reactive oxygen species inhibitory constituents of hypericum thasium griseb. Phytochem. 2009;70(2):244-249.

21. Vilela FM, Fonseca YM, Jabor JR, Vicentini FT, Fonseca MJ. Effect of ultraviolet filters on skin superoxide dismutase activity in hairless mice after a single dose of ultraviolet radiation. Eur J Pharm Biopharm. 2012;80(2):387-392.

22. Mohsin SMN, Hussein MZ, Sarijo SH, Fakurazi S, Arulselvan P, Hin TY. Characterizations and cytotoxicity assessment of UV absorbersintercalated zinc/aluminium layered double hydroxides on dermal fibroblast cells. Sci Adv Mater. 2014;6(4):1-11.

23. He Q, Yin S, Sato T. Synthesis and photochemical properties of zincaluminum layered double hydroxide/organic UV ray absorbing molecule/ silica nanocomposites. J Phys Chem Solids. 2004;65(2-3):395-402.

24. Mohsin SM, Hussein MZ, Sarijo SH, Fakurazi S, Arulselvan P, Hin TY. Synthesis of (cinnamate-zinc layered hydroxide) intercalation compound for sunscreen application. Chem Cent J. 2013;7(1):26.

25. Perioli L, Nocchetti M, Ambrogi V, Latterini L, Rossi C, Costantino U. Sunscreen immobilization on ZnAl-hydrotalcite for new cosmetic formulations. Micropor Mesopor Mat. 2008;107(1-2):180-189.

26. Rodil R, Quintana JB, López-Mahía P, Muniategui-Lorenzo S, PradaRodríguez D. Multiclass determination of sunscreen chemicals in water samples by liquid chromatography-tandem mass spectrometry. Anal Chem. 2008;80(4):1307-1315.

27. Zhang W, Wilson CR, Danielson ND. Indirect fluorescent determination of selected nitro-aromatic and pharmaceutical compounds via UV-photolysis of 2-phenylbenzimidazole-5-sulfonate. Talanta. 2008; 74(5):1400-1407.

28. Ishikawa T, Matsumoto K, Kandori K, Nakayama T. Synthesis of layered zinc hydroxide chlorides in the presence of Al(III). J Solid State Chem. 2006;179(4):1110-1118.

29. Zhang S, Chen J, Qiao X, Ge L, Cai X, Na G. Quantum chemical investigation and experimental verification on the aquatic photochemistry of the sunscreen 2-phenylbenzimidazole-5-sulfonic acid. Environ Sci Technol. 2010;44(19):7484-7490.

30. Frunza M, Hritcu D, Popa MI. Intercalation of salicylic acid into ZnAl layered double hydroxides by ion-exchange and percipitation method. J Optoelectron Adv Mat. 2009;11(4):528-534.

31. Sun W, He Q, Luo Y. Synthesis and properties of cinnamic acid series organic UV ray absorbents-interleaved layered double hydroxides. Mater Lett. 2007;61(8-9):1881-1884.

32. Arizaga GG, Mangrich AS, da Gardolinski JE, Wypych F. Chemical modification of zinc hydroxide nitrate and $\mathrm{Zn}$-Al-layered double hydroxide with dicarboxylic acids. J Colloid Interf Sci. 2008;320(1): $168-176$.
33. Touati S, Mansouri H, Bengueddach A, Roy A, Forano C, Prevot V. Nanostructured layered double hydroxide aerogels with enhanced adsorption properties. Chem Commun (Camb). 2012;48(57):7197-7199.

34. Chai H, Xu X, Lin Y, Evans DG, Li D. Synthesis and UV absorption properties of 2,3-dihydroxynaphthalene-6-sulfonate anion-intercalated $\mathrm{Zn}-\mathrm{Al}$ layered double hydroxides. Polymer Degrad Stabil. 2009;94(4):744-749.

35. Marangoni R, Taviot-Gueho C, Illaik A, Wypych F, Leroux F. Organic inorganic dye filler for polymer: Blue-coloured layered double hydroxides into polystyrene. J Colloid Interface Sci. 2008;326(2):366-373.

36. Verschooten L, Declercq L, Garmyn M. Adaptive response of the skin to UVB damage: role of the p53 protein. Int J Cosmetic Sci. 2006; 28(1):1-7.

37. Ahmed AAA, Talib ZA, Hussein MZ, Zakaria A. Zn-Al layered double hydroxide prepared at different molar ratios: preparation, characterization, optical and dielectric properties. J Solid State Chem. 2012;191:271-278.

38. Parida KM, Mohapatra L. Carbonate intercalated Zn/Fe layered double hydroxide: A novel photocatalyst for the enhanced photo degradation of azo eyes. Chem Eng J. 2012;179:131-139.

39. Shao M, Han J, Wei M, Evans DG, Duan X. The synthesis of hierarchical $\mathrm{Zn}$-Ti layered double hydroxide for efficient visible-light photocatalysis. Chem Eng J. 2011;168(2):519-524.

40. Costa P, Lobo JMS. Modeling and comparison of dissolution profiles. Eur J Pharm Sci. 2001;13(2):123-133.

41. Singh J, Gupta S, Kaur H. Prediction of in vitro drug release mechanisms from extended release matrix tablets using SSR $/ \mathrm{R}^{2}$ technique. Trends Applied Sci Res. 2011;6(4):400-409.

42. Ling L, He J, Wei M, Evans DG, Duan X. Uptake of chloride ion from aqueous solution by calcined layered double hydroxides: equilibrium and kinetic studies. Wat Res. 2006;40(4):735-743.

43. Kodama T, Harada Y, Ueda M, Shimizu K, Shuto K, Komarneni S. Selective exchange and fixation of strontium ions with ultrafine Na-4mica. Langmuir. 2001;17(16):4881-4886.

44. Park M, Kim H, Park D, Yang J, Choy J. Ketoprofen-LDH nanohybrid for transdermal drug delivery system. Bull Korean Chem Soc. 2012;33(6):1827-1828.

45. Hussein MZ, Jaafar AM, Yahaya AH, Zainal Z. The effect of single, binary and ternary anions of chloride, carbonate and phosphate on the release of 2,4-dichlorophenoxyacetate intercalated into the $\mathrm{Zn}$ Al-layered double hydroxide nanohybrid. Nanoscale Res Lett. 2009; 4(11):1351-1357.

46. Kugelmass IN. The determination of the tertiary dissociation constant of phosphoric acid. Biochem J. 1929;23(4):587-592.

47. Miyata S. Anion-exchange properties of hydrotalcite-like compounds. Clays Clay Miner. 1983;31(4):305-311.
International Journal of Nanomedicine

\section{Publish your work in this journal}

The International Journal of Nanomedicine is an international, peerreviewed journal focusing on the application of nanotechnology in diagnostics, therapeutics, and drug delivery systems throughout the biomedical field. This journal is indexed on PubMed Central, MedLine, CAS, SciSearch $\AA$, Current Contents ${ }^{\circledR} /$ Clinical Medicine,
Dovepress

Journal Citation Reports/Science Edition, EMBase, Scopus and the Elsevier Bibliographic databases. The manuscript management system is completely online and includes a very quick and fair peer-review system, which is all easy to use. Visit http://www.dovepress.com/ testimonials.php to read real quotes from published authors. 